\title{
MAPEAMENTO META-NARRATIVO DA PRODUÇÃO ACADÊMICA BRASILEIRA SOBRE FALSIFICAÇÃO
}

\author{
Wagner Vicente Diniz* \\ wagnervicentediniz@gmail.com \\ Ramon Silva Leite* \\ ramons1@pucminas.br \\ Marcelo de Rezende Pinto* \\ marcrez@hotmail.com \\ *Pontifícia Universidade Católica de Minas Gerais
}

http://dx.doi.org/10.1590/1413.2311.173.60769

Recebido em 11/12/2015

Aprovado em 19/06/2017

Disponibilizado em 07/08/2017

Avaliado pelo sistema "double blind review"

Revista Eletrônica de Administração

Editoras-chefe: Andrea Oltramari e Maria Ceci Misoczky

ISSN 1413-2311 (versão "on line")

Editada pela Escola de Administração da Universidade Federal do Rio Grande do Sul

Periodicidade: Quadrimestral

Sistema requerido: Adobe Acrobat Reader

\section{RESUMO}

O mercado de produtos falsificados tem um alcance global, apresenta crescimento significativo e desperta o interesse de diversas áreas do conhecimento. Atentos a essas questões, pesquisadores brasileiros da área de Administração têm envidado esforços para compreender melhor esse complexo fenômeno, reconhecendo que tal mercado se mostra expressivo e possibilita um amplo campo de estudo. Nesse sentido, o presente trabalho teve o objetivo de analisar, por meio de um mapeamento meta-narrativo, a produção brasileira sobre o tema falsificação. A abordagem de mapeamento meta-narrativo se baseia na revisão sistemática dos métodos e teorias, destacando suas particularidades, sendo o primeiro passo para a formação de um framework teórico. Para tanto, foi conduzido um estudo descritivo, onde foram analisados 23 artigos, 13 dissertações e uma tese. Os resultados obtidos sugerem que a falsificação é um campo de estudo fecundo, abordado por distintas áreas da administração e por pesquisadores de diferentes instituições de ensino, mas que ainda demonstra significativo potencial a ser explorado. Identificou-se que as teorias de base, no que se relaciona a falsificação, apresentam inúmeras referências que podem ser utilizadas por futuras pesquisas sobre o tema. Acredita-se que, para desenvolvimento do conhecimento sobre falsificação no Brasil, os estudos deverão buscar a interlocução com outras áreas do conhecimento, tais como estratégia, cultura organizacional, direito, sociologia e engenharia. Observou-se ainda a ausência de trabalhos que abordem a falsificação sob a perspectiva da produção e comercialização, o que seria um gap de pesquisa a ser abordado em trabalhos futuros. Por fim, acredita-se que o estudo em tela poderá servir de guia para futuras pesquisas sobre o tema.

Palavras chaves: Mapeamento meta-narrativo. Falsificação. Pirataria. Publicações brasileiras. 


\begin{abstract}
The market of counterfeit goods has a global reach, offers significant growth and attracts the interest of several areas of knowledge. Aware of these issues, Brazilian researchers in the Administration area have been endeavoring to gain a better understanding of this complex phenomenon, recognizing that such market is expressive and allows a broad field of study. In this sense, the present study aimed to analyze, through a meta-narrative mapping, the Brazilian production on the subject of falsification. The approach of meta-narrative mapping is based on the systematic review of methods and theories, emphasizing its peculiarities, being the first step towards the formation of a theoretical framework. For this purpose, a descriptive study was conducted, where 23 articles, 13 dissertations, and one thesis were analyzed. The results obtained suggest that counterfeiting is a fertile field of study, approached by different areas of management and by researchers from different educational institutions, but it still demonstrates significant potential to be explored. It was identified that the basic theories, in which relate to counterfeit, feature numerous references that can be used for further research on the subject. It is believed that, for knowledge development about counterfeiting in Brazil, studies should seek dialogue with other areas of knowledge, such as strategy, organizational culture, law, sociology, and engineering. It was also observed the absence of works dealing with the falsification from the perspective of production and commercialization, which would be a gap of research to be approached in future works. Finally, it is believed that this study could serve as a guide for future research on the topic.
\end{abstract}

Key words: Mapping meta-narrative. Counterfeiting. Piracy. Brazilian publication.

\title{
RESUMEN
}

El mercado de productos falsificados tiene un alcance global, presenta un crecimiento significativo y despierta el interés de muchas áreas del conocimiento. Conscientes de estos problemas, los investigadores brasileños de área de Gestión han hecho esfuerzos para comprender mejor este fenómeno complejo, reconociendo que tal mercado está mostrando significativa y proporciona un amplio campo de estudio. En este sentido, este estudio tuvo como objetivo analizar, a través de un mapeo meta-narrativa, la producción brasileña en la tema de falsificación. El enfoque de mapeo de meta-narrativa se basa en la revisión sistemática de los métodos y teorías, destacando sus peculiaridades, el primer paso en la formación de un marco teórico. Por lo tanto, se llevó a cabo un estudio descriptivo, que analizó 23 artículos, 13 disertaciones y una tesis. Los resultados sugieren que la falsificación es un campo fértil de estudio, abordado por diferentes áreas de la administración e investigadores de diferentes instituciones educativas, pero también muestra un importante potencial para ser explorado. Se identificó que las teorías básicas, en lo que respecta a la falsificación, tienen numerosas referencias que pueden ser utilizados para futuras investigaciones sobre el tema. Se cree que, para el desarrollo de conocimientos sobre falsificación en el Brasil, los estudios deben buscar el diálogo con otras áreas del conocimiento, como la estrategia, la cultura organizacional, derecho, sociología e ingeniería. También se observó la ausencia de trabajos que aborden la falsa desde la perspectiva de la producción y la comercialización, lo que sería un espacio de investigación que se abordarán en futuros trabajos. Por último, se cree que el estudio puede servir como guía para futuras investigaciones sobre el tema. 
Palabras clave: Mapeo meta-narrativo. Falsificación. Piratería. Publicaciones brasileñas.

\section{INTRODUÇÃO}

A prática da falsificação não é um fenômeno da economia contemporânea e pode ser observada em diversos momentos da história e em diferentes regiões. No entanto, foi com o aumento da utilização de marcas para identificar a origem e atestar autenticidade aos produtos que a prática da contrafação obteve maior estímulo (CHAUDHRY et al., 2009).

Segundo Macesich (1961), os primeiros estudos sobre contrafação abordaram a falsificação de moedas nos Estados Unidos, ainda no século XIX. Já o mercado de produtos falsificados, bem como o seu consumo, é objeto de estudos acadêmicos desde a década de 1970. Conforme Staake et al. (2009), o tema é abordado por estudos de diferentes linhas de pesquisa da Administração, tais como Marketing, Logística e Gestão Estratégica.

Conforme destacam Green e Smith (2002), falsificações propendem a fortalecer especialmente em países em desenvolvimento, onde o ambiente institucional tende a ser menos consolidado. Nesse sentido, o Brasil se apresenta como um importante player no mercado de falsificação, tanto em termos de consumo como em termos de produção (SILK, 1986; STUMPF; CHAUDHRY; PERRETTA, 2013; STUMPF; CHAUDHRY, 2010). A reboque dessas considerações, entende-se que o mercado de artigos falsificados no Brasil possibilita um amplo campo de estudos, no sentido de compreender questões relacionadas à produção, comercialização e consumo desse tipo de produto.

No intuito de compreender melhor esse fenômeno, sob as lentes dos estudos já desenvolvidos no Brasil na área de Administração, o objetivo do presente artigo foi analisar, por meio de um mapeamento meta-narrativo, a produção brasileira sobre contrafação. $\mathrm{O}$ estudo pretendeu ainda analisar: a) as características gerais da publicação; b) a natureza da coleta de dados e os métodos de análise empregados; c) as teorias de base e principais referências dos estudos; d) as sugestões dos autores para futuras pesquisas; e) as limitações dos estudos analisados, e; f) os avanços para o entendimento do fenômeno.

A abordagem de mapeamento meta-narrativo se baseia na revisão sistemática dos métodos e teorias, destacando suas particularidades, sendo o primeiro passo para a formação de um framework teórico (PETTICREW; ROBERTS, 2006). Estudos que buscam sintetizar o conhecimento científico já foram realizados por pesquisadores brasileiros, por exemplo: Bertero, Caldas e Wood Jr. (1999), Davel e Alcadipani (2003), Pinto e Lara (2007) e Sampaio e Perin (2006). Este fato manifesta a preocupação constante dos acadêmicos brasileiros da área de Administração, no sentido de reavaliar a sua postura e procedimentos em relação à sua 
própria pesquisa acadêmica, bem como revisitar a produção acadêmica nacional em Administração (SAMPAIO; PERIN, 2006).

Além disso, estudos de mapeamento meta-narrativo podem ser capazes de identificar e alavancar determinado campo científico, pois a revisão sistemática inerente a esse método de investigação contribui na identificação de gaps de pesquisa. Nesse sentido, espera-se que o presente trabalho, que se baseia no mapeamento meta-narrativo das produções científicas brasileiras sobre falsificação, possa servir como um guia a ser utilizado por pesquisadores, profissionais e demais envolvidos com a questão da falsificação.

Para o mapeamento, foram pesquisados artigos indexados no Scientific Periodicals Electronic Library (Spell), Scientific Electronic Library Online (SciELO) e nos encontros da Associação Nacional de Pós-Graduação e Pesquisa em Administração (ANPAD). Em relação às Teses e Dissertações (T\&D), foram pesquisados todos os programas de Pós-Graduação filiados à ANPAD.

O trabalho foi estruturado em cinco tópicos, iniciando por esta introdução. O segundo aborda o mercado de falsificação, demonstrando, por meio de dados recentes, a expressividade de tal segmento no Brasil e no mundo. O terceiro tópico apresenta a metodologia de pesquisa utilizada. O quarto dispõe os resultados da pesquisa e o último apresenta as discussões e considerações finais.

\section{O MERCADO DE FALSIFICAÇÃO}

As dimensões e estruturas do comércio de produtos falsificados avançaram nos últimos anos por meio da internet; estima-se que, em 2015, a superação de 1 trilhão de dólares comercializados no mundo em produtos falsificados (BASCAP, 2011; RADON, 2012; TSAI; CHIOU, 2012). No entanto, a contrafação não é um problema estritamente do século XXI. Trata-se de um problema histórico, pois a falsificação de produtos de luxo data do ano 27 antes da nossa era, onde o vinho produzido em Gaul era falsificado e vendido em Roma (como vinho romano) a um valor maior (WILCOX; KIM; SEN, 2009). Há também registros que no século XVII, o padre espanhol Domingo Navarette documentou a habilidade com que os chineses produziam cópias (CHAUDHRY, 2006; ECONOMIST, 2015).

Com o desenvolvimento da internet, aliado à capacidade histórica de produzir cópias e a fatores culturais favoráveis, a China é hoje o principal player do mercado global de falsificação (ANWAR MIR, 2013). Além disso, naquele país a infração à propriedade intelectual não é entendida como moralmente errada ou criminosa (CHAUDHRYet al., 2009).

Além da China, outro player importante do mercado global de falsificação são os REAd | Porto Alegre - Edição 86 - No 2 - Maio / Agosto 2017 - p. 135 - 166 
Estados Unidos, não só como produtor, mas como consumidor (ANWAR MIR, 2013). Taiwan, Hong Kong, Singapura, Filipinas, Coreia do Sul, Itália, Tailândia, Índia, Japão, Indonésia, Brasil, Colômbia, México e Nigéria também são players relevantes no mercado de produtos falsificados (SILK, 1986; STUMPF; CHAUDHRY, 2010; STUMPF; CHAUDHRY; PERRETTA, 2013).

Conforme pode ser observado na Tabela 1, o comércio mundial de produtos falsificados avançou cerca de 390\%, tendo em vista o período de 2008 à 2015.

Tabela 1: Estimativa do valor total do mercado de produtos pirateados

\begin{tabular}{l|c|c}
\hline \multicolumn{1}{c|}{ Categorias OECD } & $\begin{array}{c}\text { Estimativa em US\$ } \\
\text { bilhões (2008) }\end{array}$ & $\begin{array}{c}\text { Estimativa em US\$ } \\
\text { bilhões (2015) }\end{array}$ \\
\hline Comércio internacional de produtos falsificados & $285-360$ & $770-1.770$ \\
Produção e consumo doméstico de produtos falsificados & $140-215$ & $370-570$ \\
Produtos digitais falsificados & $30-75$ & $80-240$ \\
\hline Efeitos globais com proteção \pm & 125 & 125 \\
Perda de vagas de empregos $\times$ & 2.5 milhões & 2.5 milhões \\
\hline
\end{tabular}

Fonte: adaptado pelos autores de BASCAP (2011).

\pm Efeitos globais com proteção incluem: gastos com repressão, custos com os crimes e impostos.

$\times$ A estimativa se limita as 20 maiores economias do mundo.

Quando se observa a produção e consumo doméstico de produtos falsificados, leva-se em consideração o consumo interno das vinte maiores economias do mundo, e os efeitos globais com proteção, gastos dessas economias com fiscalização, repressão, investigações etc., objetivando a redução do mercado de produtos falsificados. No entanto, os números acerca desse mercado provêm de estimativas conservadoras (BASCAP, 2011).

As atividades relacionadas à pirataria e falsificação fizeram com que o Governo Federal brasileiro deixasse de arrecadar R $\$ 30$ bilhões de reais em 2013, sendo R $\$ 8$ bilhões de reais somente em tributação sob óculos (FNCP, 2015). Na Inglaterra, o mercado ilegal de produtos falsificados resultou na perda de 10 bilhões de libras em 2003 (BIAN; VELOUTSOU, 2007). Já para o governo estadunidense, estima-se de 200 a 250 bilhões de dólares em perdas em 2015 (BASCAP, 2011).

Pesquisadores de diferentes nacionalidades, reconhecendo a relevância de tal setor para os estudos ligados à Administração, desenvolveram trabalhos no sentido de mapear as pesquisas sobre tal temática. Eisend e Schuchert-Güler (2006) revisaram uma série de estudos sobre os determinantes da intenção dos consumidores em comprar produtos falsificados, no intuito de fornecer uma visão mais ampla sobre o tema e identificar possíveis lacunas. De forma similar, Lee e Yoo (2009) buscaram, por meio de uma revisão da literatura sobre o mercado de falsificação, propor tópicos específicos a serem investigados em futuras pesquisas. Já Staake, Thiesse e Fleisch (2009) pretenderam esclarecer os princípios 
econômicos do comércio de produtos contrafeitos, assim como das cadeias de abastecimento ilícitas subjacentes. Para isso, foi realizada uma extensa revisão da literatura, que incluiu contribuições de diferentes vertentes de pesquisa em gestão. Tais estudos demonstram que o tema é amplo e que merece maior atenção por parte de pesquisadores da Administração e de outras áreas correlatas. No entanto, para a realidade brasileira, não há estudos que mapearam as publicações nacionais. Além disso, os três estudos elencados anteriormente não analisaram boa parte da publicação brasileira, devido à barreira do idioma. Dessa forma, constata-se que o presente trabalho vem preencher uma lacuna de estudos, no intuito de fornecer um panorama das publicações nacionais da área de Administração sobre o fenômeno da falsificação.

\section{DESENHO DA PESQUISA}

A presente pesquisa utilizou da abordagem descritiva, com base em mapeamento metanarrativo. Tratando-se de uma nova abordagem, o mapeamento meta-narrativo pode ser utilizado para buscar novas evidências e técnicas de pesquisa, envolvendo conceitos chaves, teorias, elementos e achados. Sua utilização se dá com o objetivo de abordar criticamente os estudos sobre determinada temática (PETTICREW; ROBERTS, 2006).

A busca por artigos, Dissertações e Teses iniciou pela consulta em bancos de dados com as palavras chaves: falsificado, falsificação, pirata, pirataria e contrafação, que são termos comumente utilizados para caracterização do fenômeno. O período de busca se deu em duas fases distintas, sendo a primeira entre os meses de agosto e outubro de 2014 e a segunda entre janeiro e julho de 2015. Objetivou-se, com isso, obter um maior número de trabalhos, tendo em vista a possibilidade de novas indexações de artigos, Dissertações e Teses.

As produções analisadas foram categorizadas entre Teses, Dissertações e Artigos, sendo; A para artigos, D para dissertações e T para teses.

No tocante aos artigos, optou-se por realizar a pesquisa em artigos indexados na Scientific Periodicals Electronic Library (Spell), Scientific Electronic Library Online (SciElO) e no Encontro Nacional da Associação Nacional de Pós-Graduação e Pesquisa em Administração (ENANPAD) e foram organizados no Quadro 1.

Os critérios para seleção de artigos foram, para inclusão: (1) serem artigos científicos; (2) terem sido publicados em português; (3) ter o texto completo disponível para acesso e (4) o resumo ter uma ou mais palavras chaves utilizadas na busca. Com base nesses critérios foram encontrados 30 artigos.

Como critérios para exclusão foram considerados: (1) artigos que não abordavam REAd | Porto Alegre - Edição 86 - No 2 - Maio / Agosto 2017 - p. 135 - 166 
diretamente a pirataria; (2) artigos que não fossem publicados em eventos da ANPAD ou em revistas científicas listadas no Qualis da área da Administração, Ciências Contábeis e Turismo, e (3) artigos não científicos. Após a aplicação dos critérios de exclusão, foram selecionados 23 artigos, sendo que esses compuseram o corpus da pesquisa.

Quadro 1: Lista dos artigos considerados na pesquisa

\begin{tabular}{|c|c|}
\hline Código & Artigo \\
\hline A1 & $\begin{array}{l}\text { ALVIM, B. C. B.; STREHLAU, S.; KIRSCHBAUM, C. Downloads legais versus ilegais: como } \\
\text { aumentar a legalidade no consumo de música? REAd, v. 2, n. 75, p. 330-350, } 2013 \text {. }\end{array}$ \\
\hline $\mathrm{A} 2$ & $\begin{array}{l}\text { BARROS, D. F. et al. Download, pirataria e resistência: uma investigação sobre o consumidor de } \\
\text { música digital. Comunicação, Mídia e Consumo, v. } 7 \text {, n. } 18 \text {, p. 125-151, } 2010 .\end{array}$ \\
\hline A3 & $\begin{array}{l}\text { BAZANINI, R. et al. Uma reflexão sobre a intenção de compra de produtos piratas pelo público jovem } \\
\text { para detectar futuras estratégias de combate. Encontro de Marketing da ANPAD, p. 1-13, } 2006 \text {. }\end{array}$ \\
\hline A4 & $\begin{array}{l}\text { CASALI, R. DO R. B. et al. Pirataria de software: uma análise da relação entre comportamento ético, } \\
\text { atitude e intenção do consumidor. Encontro Nacional da ANPAD, p. 1-14, } 2010 .\end{array}$ \\
\hline A5 & $\begin{array}{l}\text { CASALI, R. DO R. B.; COSTA, F. J. DA. Uma análise dos impactos da estrutura de custos percebida } \\
\text { sobre a predisposição à pirataria de software. Encontro de Marketing da ANPAD, p. 1-16, } 2014 .\end{array}$ \\
\hline A6 & $\begin{array}{l}\text { COSTA, L. M. A pirataria do nome de domínio na internet. Revista de Administração de Empresas, } \\
\text { v. } 41, \text { n. } 1, \text { p. } 45-53,2001 .\end{array}$ \\
\hline A7 & $\begin{array}{l}\text { COSTA, R. R. C.; SANT’ANNA, S. R. O “legal” do pirata: um olhar sobre as práticas. Encontro de } \\
\text { Marketing da ANPAD, p. 1-16, 2008. }\end{array}$ \\
\hline A8 & $\begin{array}{l}\text { FILGUEIRAS, L. M.; SILVA, J. F. DA. Análise estratégica das gravadoras no Brasil: posicionando a } \\
\text { pirataria e troca gratuita de música em formato MP3. Encontro Nacional da ANPAD, p. 1987-2000, } \\
2002 .\end{array}$ \\
\hline A9 & $\begin{array}{l}\text { GIGLIO, E. M.; RYNGELBLUM, A. L. Uma investigação sobre o ator consumidor na rede de } \\
\text { pirataria e uma proposta de alternativa de estratégia de combate. Revista de Administração } \\
\text { Mackenzie, v. 10, n. 4, p. 131-155, } 2009 .\end{array}$ \\
\hline A10 & $\begin{array}{l}\text { GOMES, S. C.; STREHLAU, S. Avaliação das alternativas de compra: entre a falsificação e o original. } \\
\text { Revista Brasileira de Marketing. São Paulo Revista Brasileira de Marketing, } 14 \text { fev. 2012. Disponível } \\
\text { em: <http://www.revistabrasileiramarketing.org/ojs-2.2.4/index.php/remark/article/view/2274>. Acesso } \\
\text { em: } 23 \text { nov. } 2014\end{array}$ \\
\hline A11 & $\begin{array}{l}\text { GROHMANN, M. Z. et al. Os jovens e a pirataria: investigando o uso não autorizado de software. } \\
\text { Revista de Administração da UNIMEP, v. 13, n. 1, p. 67-90, } 2015 .\end{array}$ \\
\hline A12 & $\begin{array}{l}\text { MACHADO, S. G. D. M. a Gestão Estratégica E a Pirataria: Integração Estratégica, Estrutura } \\
\text { Organizacional eas Atividades Políticas. Encontro Nacional da ANPAD, p. 1-16, } 2012 .\end{array}$ \\
\hline A13 & $\begin{array}{l}\text { MACHADO, S. G. DA M.; BAZUCHI, K. R. V. A Internacionalização das Estratégias de } \\
\text { Enfrentamento da Pirataria: um Estudo de Caso nas Empresas Farmacêuticas Multinacionais no Brasil. } \\
\text { Encontro Nacional da ANPAD, p. 1-15, 2012. }\end{array}$ \\
\hline A14 & $\begin{array}{l}\text { MACHADO, S. G. DA M.; MELLO, R. B. DE. A Gestão Estratégica e a Ilegalidade: um estudo de } \\
\text { caso do combate à pirataria no Brasil. Revista Brasileira de Gestão de Negócios, v. 15, n. 47, p. 186- } \\
\text { 203, 2013. }\end{array}$ \\
\hline A15 & $\begin{array}{l}\text { MATOS, C. A. DE; ITUASSU, C. T. Comportamento do consumidor de produtos piratas: os fatores } \\
\text { influenciadores das atitudes e das intenções de compra. Encontro Nacional da ANPAD, n. 2004, p. 1- } \\
\text { 16, } 2005 \text {. }\end{array}$ \\
\hline A16 & $\begin{array}{l}\text { RYNGELBLUM, A. L. Tratamento da Pirataria pelas Empresas e pelas Teorias de Estratégia. 3Es, p. } \\
1-15,2005 .\end{array}$ \\
\hline A17 & $\begin{array}{l}\text { RYNGELBLUM, A. L. Influências "Heterorracionais" sobre as Organizações e seu Tratamento pelas } \\
\text { Teorias de Estratégia: o caso da Pirataria. RAC-Eletrônica, v. 1, n. 2, p. 66-80, } 2007 .\end{array}$ \\
\hline A18 & $\begin{array}{l}\text { RYNGELBLUM, A. L.; GIGLIO, E. M. Análise da viabilidade estratégica do plano antipirataria do } \\
\text { Conselho Nacional de Combate à Pirataria. Encontro Nacional da ANPAD, p. 1-16, } 2006 .\end{array}$ \\
\hline A19 & $\begin{array}{l}\text { RYNGELBLUM, A. L.; GIGLIO, E. M. As Políticas Públicas no Combate à Pirataria: Reflexões sobre } \\
\text { a Prática da Gestão Pública. Encontro Nacional de Estudos Organizacionais da ANPAD, p. 1-16, } \\
2008 .\end{array}$ \\
\hline A20 & $\begin{array}{l}\text { SAUERBRONN, J. F. R. et al. Pirataria e Download como comportamento desviante e as técnicas de } \\
\text { neutralização usadas pelos consumidores. Revista Gestão e Sociedade, v. 4, n. 8, p. 1-26, } 2010 .\end{array}$ \\
\hline
\end{tabular}




\begin{tabular}{c|l}
\hline A21 & $\begin{array}{l}\text { STREHLAU, S. } \text { et al. Prontidão ao consumo de marcas de luxo falsificadas. Revista de } \\
\text { Administração da UNIMEP, v. 12, n. 2, p. 182-206, 2014. }\end{array}$ \\
\hline A22 & $\begin{array}{l}\text { STREHLAU, S.; PETERS FILHO, T. A. Valor para o Cliente de Artigos de Luxo Falsificados: Entre o } \\
\text { blefe e o prestígio. Encontro de Marketing da ANPAD, p. 1-13, 2006. }\end{array}$ \\
\hline A23 & $\begin{array}{l}\text { TRINDADE, T. D. O. Identidades e representações: significados associados ao consumo de pirataria. } \\
\text { Encontro de Marketing da ANPAD, p. 1-16, 2008. }\end{array}$ \\
\hline
\end{tabular}

Fonte: desenvolvido pelos autores (2015).

Em relação aos artigos publicados em eventos, alguns não foram considerados, pois não dispunham do conteúdo de forma integral. Quanto às Dissertações e Teses, foram considerados todos os programas de Pós-Graduação em Administração filiados à Associação Nacional de Pós-Graduação e Pesquisa em Administração (ANPAD), sendo que do total de 99 programas, em 85 foi possível a pesquisa online, mas 14 programas não dispunham de banco de Teses e Dissertações no período da pesquisa, o que impossibilitou a pesquisa nestes.

Os critérios para inclusão de dissertações foram: (1) dissertações e tese em português, (2) texto completo disponível para acesso e (3) o resumo ter uma ou mais das palavras chaves utilizadas na busca. Dessa forma, foram encontrados inicialmente 24 dissertações e 5 teses.

Como critérios para exclusão foram considerados: (1) dissertações e teses que não abordavam diretamente a pirataria e (2) dissertações e teses não defendidas em Programas de Pós-Graduação em Administração. Após a aplicação dos critérios de exclusão, foram selecionadas 13 dissertações e uma tese, listadas nos Quadro 2 e 3 a seguir.

Quadro 2: Lista de códigos das dissertações e tese

\begin{tabular}{c|l}
\hline Código & \multicolumn{1}{c}{ Dissertação } \\
\hline D1 & $\begin{array}{l}\text { CASALI, R. DO R. B. Responsabilidade social do consumidor: conceituação e proposta de } \\
\text { mensuração. João Pessoa/PB, Brasil: Universidade Federal da Paraíba, 2011. }\end{array}$ \\
\hline D2 & $\begin{array}{l}\text { FERREIRA, M. C. DE B. A falsa ilusão de ter: investigando os tipos de valor para o consumidor de } \\
\text { falsificações. Rio de Janeiro, Brasil: Fundação Getúlio Vargas, 2007. }\end{array}$ \\
\hline D3 & $\begin{array}{l}\text { GALHANONE, R. F. Atitudes, emoções e comportamento de compra: um estudo com } \\
\text { consumidores de produtos de luxo ou sofisticados. São Paulo, Brasil: Universidade de São Paulo, } \\
\text { 2008. }\end{array}$ \\
\hline D4 & $\begin{array}{l}\text { JUNQUEIRA, R. B. Identidade pirata: um estudo sobre o consumidor de roupas e acessórios } \\
\text { falsificados - suas intenções pessoais e sociais. Faculdades Integradas de Pedro Leopoldo, p. 1-128, } \\
\text { 2012. }\end{array}$ \\
\hline D5 & $\begin{array}{l}\text { KIKKO, V. O. O futuro da indústria da música no Brasil. São Paulo, Brasil: Fundação Getúlio } \\
\text { Vargas, 2012. }\end{array}$ \\
\hline D6 & $\begin{array}{l}\text { LANNES, W. V. A crise e as novas fronteiras para a indústria fonográfica. Rio de Janeiro, Brasil: } \\
\text { Fundação Getúlio Vargas, 2009. }\end{array}$ \\
\hline D7 & $\begin{array}{l}\text { LEITE, A. R. DO A. Jogo Justo: o materialismo e a Responsabilidade Social do Consumidor no } \\
\text { Consumo de Videogames Piratas.Universidade Federal da Paraíba. Brasil, 2012. }\end{array}$ \\
\hline D8 & $\begin{array}{l}\text { MACHADO, S. G. DA M. A gestão estratégica e o enfrentamento da ilegalidade: um estudo de } \\
\text { caso do combate à pirataria nas empresas farmacêuticas multinacionais no Brasil. São Paulo, Brasil: } \\
\text { Fundação Getúlio Vargas, 2011. }\end{array}$ \\
\hline D9 & $\begin{array}{l}\text { MARTINS, A. M. DE P. Identidade e imagem das marcas de luxo: um estudo sobre a Louis } \\
\text { Vuitton. São Paulo, Brasil: Fundação Getúlio Vargas, 2009. }\end{array}$ \\
\hline D10 & $\begin{array}{l}\text { MARTINS, J. P. C. O mercado de música digital brasileiro: um estudo sobre o comportamento } \\
\text { brasileiro. Porto Alegre, Brasil: Universidade Federal do Rio Grande do Sul, 2012. }\end{array}$ \\
\hline
\end{tabular}




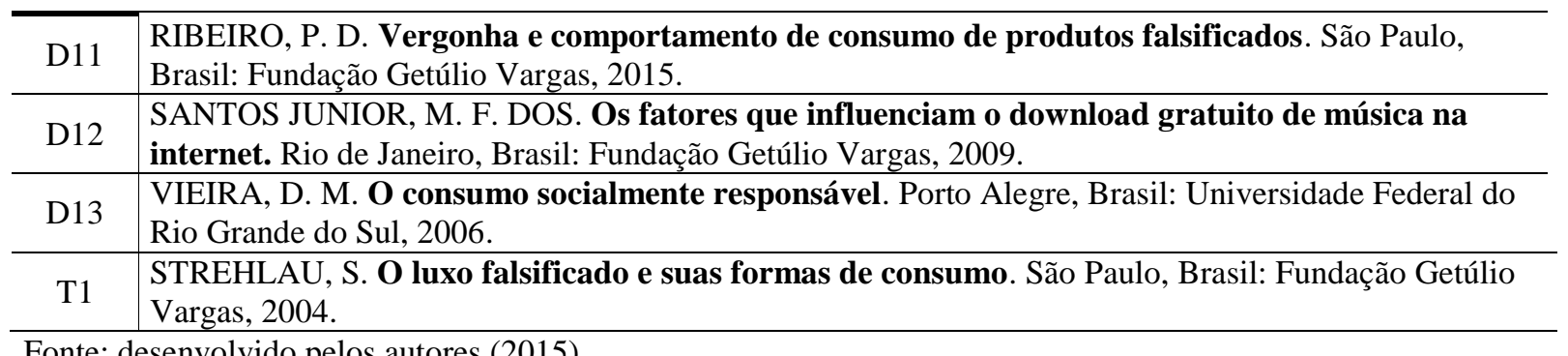

Fonte: desenvolvido pelos autores (2015).

Dessa forma, foram selecionados ao todo 37 trabalhos, sendo 23 artigos, 13 Dissertações e uma Tese, que constituíram o corpus final da pesquisa.

Para a análise dos dados, foram considerados, a priori, os aspectos gerais sobre as publicações, quais sejam: (1) fonte da publicação (Instituição de Ensino Superior (IES), periódico ou evento em que o trabalho foi publicado), (2) objeto de estudo e (3) recorte da pesquisa. Já a metodologia dos trabalhos foi analisada levando em consideração: (4) natureza de pesquisa, (5) forma de coleta de dados e (6) tipo de análise de dados. No que se relaciona à teoria, foi considerado (7) as teorias de base e as principais referências utilizadas. E, por fim, para ampliação da temática, enquanto área de estudo, foram considerados (8) as limitações nos estudos, (9) as recomendações de futuras pesquisas e (10) as contribuições e avanços. Verificou-se, por fim, (11) quais trabalhos serviram de referência para os demais, assim como (12) os pesquisadores nacionais com maior número de trabalhos relacionados ao tema.

\section{RESULTADOS}

Optou-se pela análise separada de Teses e Dissertações, por considerar que a estrutura das mesmas é diferentes da dos artigos. A análise dos resultados inicia-se pelo mapeamento dos artigos, para posteriormente analisar as dissertações e tese.

\subsection{Artigos: mapeamento meta-narrativo}

O Quadro 3 especifica o evento ou periódico da área de Administração em que os artigos analisados foram publicados.

Quadro 3: Periódicos e eventos que publicaram sobre falsificação

\begin{tabular}{r|c}
\hline \multicolumn{1}{c|}{ Código } & Origem da publicação \\
\hline A5, A8, A12, A13, A15 e A19 & Encontro Nacional da ANPAD \\
\hline A3, A4, A7, A21 e A23 & Encontro de Estudos de Marketing da ANPAD \\
\hline A22 e A11 & Revista de Administração da UNIMEP \\
\hline A16 & Encontro de Estudos em Estratégia da ANPAD \\
\hline A18 & Encontro Nacional de Estudos Organizacionais da ANPAD \\
\hline A2 & Revista Comunicação Mídia e Consumo \\
\hline A17 & Revista de Administração Contemporânea - Eletrônica \\
\hline A1 & Revista Eletrônica de Administração - UFRGS
\end{tabular}

REAd | Porto Alegre - Edição 86 - No 2 - Maio / Agosto 2017 - p. 135 - 166 


\begin{tabular}{r|l}
\hline A14 & Revista Brasileira de Gestão de Negócios \\
\hline A10 & Revista Brasileira de Marketing \\
\hline A6 & Revista de Administração de Empresas \\
\hline A9 & Revista de Administração Mackenzie \\
\hline A20 & Revista Gestão e Sociedade \\
\hline
\end{tabular}

Fonte: desenvolvido pelos autores (2015).

Como se observa, foram nove periódicos que publicaram artigos sobre a temática nos últimos 15 anos. Constata-se, no entanto, que os Encontros promovidos pela ANPAD foram os espaços mais recorrentes para publicação de trabalhos relacionados ao tema. Percebe-se também que há predominância de estudos sobre falsificação na área de marketing, mas foram encontrados também estudos sobre contrafação publicados em eventos da área de Estratégia, Comunicação e Estudos Organizacionais. Observa-se, nesse caso, a possível interlocução com diferentes áreas, demonstrando que o fenômeno é multifacetado, permitindo diferentes perspectivas.

No que se relaciona ao objeto de estudo, pode-se observar diversas abordagens, como apresentado no Quadro 4.

Quadro 4: Objeto de estudo

\begin{tabular}{l|l}
\hline \multicolumn{1}{c|}{ Código } & \multicolumn{1}{c}{ Objeto de estudo } \\
\hline A3, A9, A14, A16, A17, A18 e A19 & Combate à Falsificação \\
\hline A1, A2, A8 e A20 & Indústria Fonográfica \\
\hline A7, A15 e A23 & Consumo geral de falsificados (não há indicação de item) \\
\hline A11, A4 e A5 & Software \\
\hline A22 e A21 & Produtos de Luxo \\
\hline A12 e A13 & Indústria Farmacêutica \\
\hline A10 & Óculos Solares \\
\hline A6 & Pirataria de domínio na internet \\
\hline
\end{tabular}

Fonte: desenvolvido pelos autores (2015).

Observa-se que há predominância de estudos que abordam a falsificação sob o ponto de vista da repressão e combate. Nota-se, porém, que a pirataria digital (software, indústria fonográfica e pirataria de domínio na internet) também é debatida de forma significativa pelos pesquisadores nacionais.

No que se relaciona ao recorte da pesquisa, buscando verificar se o estudo aborda a demanda ou a oferta de itens falsificados, pode-se observar no Quadro 5 que os estudos apresentam, em sua maioria, o recorte pelo lado da demanda (consumo), não tendo observado nenhum estudo que teve como foco analisar a produção ou a comercialização de produtos falsificados.

Quadro 5: Recorte de pesquisa

\begin{tabular}{|c|c|}
\hline Código & Recorte da pesquisa \\
\hline $\begin{array}{r}\mathrm{A} 1, \mathrm{~A} 2, \mathrm{~A} 3, \mathrm{~A} 4, \mathrm{~A} 5, \mathrm{~A} 6, \mathrm{~A} 7, \mathrm{~A} 9, \mathrm{~A} 10, \mathrm{~A} 11, \mathrm{~A} 15, \mathrm{~A} 20 \\
\mathrm{~A} 21, \mathrm{~A} 22 \text { e A23 }\end{array}$ & Consumo de produtos falsificados (demanda) \\
\hline
\end{tabular}

REAd | Porto Alegre - Edição 86 - Nº 2 - Maio / Agosto 2017 - p. 135 - 166 
\begin{tabular}{r|l}
\hline A8, A12, A13, A14, A16 e A17 & Concorrência entre organizações legítimas e ilegais \\
\hline A18 e A19 & Governo \\
\hline
\end{tabular}

Fonte: desenvolvido pelos autores (2015).

A possibilidade de pesquisas que adotem o recorte pelo lado da oferta poderia trazer descobertas sobre a produção dos itens falsificados. Duas publicações analisadas adotaram como recorte o papel e práticas do Governo em relação ao mercado de falsificado.

Em relação à análise da metodologia dos artigos, buscou-se inicialmente identificar as abordagens em que se basearam as pesquisas. É importante destacar que o artigo A6 é um trabalho teórico, que não contemplou a aplicação de pesquisa empírica. Dessa forma, não foi avaliado sob a perspectiva da natureza da pesquisa. O Quadro 6 mostra que as pesquisas de natureza quantitativa foram as mais adotadas e que três produções se basearam em pesquisa qualitativa e quantitativa.

Quadro 6: Natureza da pesquisa

\begin{tabular}{|c|c|}
\hline Código & Natureza da pesquisa \\
\hline $\mathrm{A} 1, \mathrm{~A} 2, \mathrm{~A} 7, \mathrm{~A} 8, \mathrm{~A} 9, \mathrm{~A} 10, \mathrm{~A} 12, \mathrm{~A} 13, \mathrm{~A} 14, \mathrm{~A} 18, \mathrm{~A} 19, \mathrm{~A} 20, \mathrm{~A} 21$ e $\mathrm{A} 23$ & Quantitativa \\
\hline A4, A5, A6, A11, A15, A16, A17 e A22 & Qualitativa \\
\hline A3 e A16 e A17 & Qualitativa e Quantitativa \\
\hline
\end{tabular}

Fonte: desenvolvido pelos autores (2015).

Apesar do número de estudos qualitativos ser menor em relação aos estudos quantitativos, observa-se o uso predominante da metodologia estudo de caso. Foi observado também que as amostras das pesquisas foram constituídas, em sua maioria, por estudantes selecionados de forma não probabilística.

Os métodos de coleta de dados empregados pelas pesquisas estão dispostos no Quadro 8.

Quadro 7: Métodos de coleta de dados

\begin{tabular}{r|l}
\hline \multicolumn{1}{c}{ Código } & \multicolumn{1}{c}{ Coleta de dados } \\
\hline $\mathrm{A} 7, \mathrm{~A} 10, \mathrm{~A} 12, \mathrm{~A} 13, \mathrm{~A} 14, \mathrm{~A} 18$ e A23 & Entrevista semiestruturada \\
\hline $\mathrm{A} 1, \mathrm{~A} 3, \mathrm{~A} 4, \mathrm{~A} 5, \mathrm{~A} 11, \mathrm{~A} 15$ e A22 & Levantamento (survey) \\
\hline $\mathrm{A} 2, \mathrm{~A} 9$ e A20, & Grupo de Foco \\
\hline A8 e A21 & Entrevista em profundidade \\
\hline A19 & Pesquisa documental \\
\hline A6, A16 e A17 & Outras \\
\hline
\end{tabular}

Fonte: desenvolvido pelos autores (2015).

Como é possível observar no Quadro 7, os métodos de coleta de dados mais utilizados foram entrevista em profundidade e levantamento. Cabe destacar que os estudos de natureza qualitativa adotaram, em sua maioria, entrevista semiestruturada e grupos de foco como métodos de coleta de dados. Nota-se que a pesquisa de natureza qualitativa permitiu, dentre os artigos analisados, maior heterogeneidade de métodos de coleta de dados. 
Em relação às teorias de base e principais referências utilizadas pelos artigos nacionais analisados, pode-se observar significativa heterogeneidade nas referências e conceitos de base, o que pode ser observado no Quadro 8.

Quadro 8: Teorias de base e referências dos artigos

\begin{tabular}{|c|c|c|}
\hline Cód. & Ref. & Teorias de base e referências \\
\hline A1 & $\begin{array}{l}\text { Alvim et al. } \\
\text { (2013). }\end{array}$ & Experiência na internet: Constantinides e Geurts (2005). \\
\hline A2 & $\begin{array}{l}\text { Barros et al. } \\
\text { (2010). }\end{array}$ & $\begin{array}{l}\text { Mercado Fonográfico: Barros (2004). } \\
\text { Temática do Napster: Leal(2005). } \\
\text { Resistência do consumidor: Friedman (1985); Hirchman (1973); Ritson e Dobscha } \\
\text { (1999) e Fournier (1998). }\end{array}$ \\
\hline A3 & $\begin{array}{l}\text { Bazanini et } \\
\text { al. (2006). }\end{array}$ & Modelo de consumo em etapas: Szafir-Goldstein (2000). \\
\hline A4 & $\begin{array}{l}\text { Casali et al. } \\
(2010) \text {. }\end{array}$ & $\begin{array}{l}\text { Origem da pirataria: Orrico(2004). } \\
\text { Desdobramentos da pirataria de software: Nill e Shultz (2009). }\end{array}$ \\
\hline A5 & $\begin{array}{l}\text { Casali } \\
\text { Costa } \\
(2014)\end{array}$ & $\begin{array}{l}\text { Ética em marketing: Vitell (1986). } \\
\text { Comportamento ético do consumidor: Vitell (2003; 2006). } \\
\text { Pirataria de software: Shore et al. (2001); Gupta, Gould e Pola (2004); Peitz e } \\
\text { Waellbroeck (2006). }\end{array}$ \\
\hline A6 & $\begin{array}{l}\text { Costa } \\
(2001)\end{array}$ & $\begin{array}{l}\text { Internet e Registro de Domínio: Anatel, Legislação Brasileira sobre Internet e } \\
\text { Instituto Nacional de Propriedade Industrial. } \\
\text { Pirataria: Santa Rosa (1999). }\end{array}$ \\
\hline A7 & $\begin{array}{l}\text { Costa e } \\
\text { Sant'Anna } \\
(2008) \text {. }\end{array}$ & Consumo: Rocha (2005), Miller (2002); Boudrillard (1991) e Campbell (2000). \\
\hline A8 & $\begin{array}{l}\text { Filgueiras e } \\
\text { Silva } \\
(2002) \text {. }\end{array}$ & Análise estratégica: Porter $(1979 ; 1980 ; 1985 ; 1991 ; 1996 ; 1997$ e 2001). \\
\hline A9 & $\begin{array}{l}\text { Giglio e } \\
\text { Ryngelblum } \\
(2009) \text {. }\end{array}$ & $\begin{array}{l}\text { Conceitos sobre rede: Burt (1976) e Tichy, Tushman e Fombrun (1979). } \\
\text { Consumo no conceito de redes: Granovetter (1973); Castells (1999) e Gulati e } \\
\text { Gargiulo (1999). }\end{array}$ \\
\hline A10 & $\begin{array}{l}\text { Gomes e } \\
\text { Strehlau } \\
\text { (2014). }\end{array}$ & $\begin{array}{l}\text { Falsificação: Cordell et al. (1996) e Grossman e Shapiro (1988). } \\
\text { Teoria dos Prospectos: Kahneman e Tversky (1979) e Tversky e Kahneman (1981). }\end{array}$ \\
\hline A11 & $\begin{array}{l}\text { Grohmann } \\
(2015) \text {. }\end{array}$ & $\begin{array}{l}\text { Pirataria de software: Gupta, Gould e Pola (2004); Casali et al. (2010); Phau e Ng } \\
\text { (2010), Chen, Pan e Pan (2009); Logsdon, Thompson e Reid (1994) e Suki, Ramayah e } \\
\text { Suki (2011). }\end{array}$ \\
\hline A12 & $\begin{array}{l}\text { Machado } \\
(2012)\end{array}$ & $\begin{array}{l}\text { Integração das estratégias de mercado e não-mercado: Baron e Winter (1995). } \\
\text { Modelo de abordagem, participação e decisão estratégica para não mercado: } \\
\text { Hillman e Hitt (1999). } \\
\text { Estrutura da relação matriz-subsidiária: Pelmutter (1969)e Bartlett e Ghoshal } \\
\text { (1989). }\end{array}$ \\
\hline A13 & $\begin{array}{l}\text { Machado } \\
\text { Bazuchi } \\
(2012)\end{array}$ & [Idêntico ao A12] \\
\hline A14 & $\begin{array}{l}\text { Machado } \\
\text { Mello } \\
(2013) \text {. }\end{array}$ & [Idêntico ao A13] \\
\hline A15 & $\begin{array}{l}\text { Matos e } \\
\text { Ituassu } \\
(2005)\end{array}$ & $\begin{array}{l}\text { Atitudes e intenções comportamentais: Bagozzi, Gürhan-Canli e Priester (2002), } \\
\text { Petty e Cacioppo (1981) e Blackwell, Miniard e Engel (2005). } \\
\text { Atitudes em relação a produtos piratas: Ang et al. (2001) e Huang, Lee e Ho (2004). }\end{array}$ \\
\hline A16 & $\begin{array}{l}\text { Ryngelblum } \\
(2005) \text {. }\end{array}$ & $\begin{array}{l}\text { Modelo do Design, Planejamento e Posicionamento: Mintzberg, Ahlstrand, e Lampel } \\
\text { (2000); Ansoff (1965) e Porter (1989). } \\
\text { Ecologia Populacional: Hannan e Freeman (1977). } \\
\text { Teoria da Dependência de Recursos: Pfeffer e Salancik (1978). } \\
\text { Teoria dos Stakeholders: Freeman (1984). }\end{array}$ \\
\hline
\end{tabular}




\begin{tabular}{|c|c|c|}
\hline & & $\begin{array}{l}\text { Modelos de Rede de Empresas: Ebers e Jarillo(1998); Achrol e Kotler (2000); } \\
\text { Anderson e Narus, (1990); Dwyer, Schurr, e Oh (1987) e Nohria (1992). } \\
\text { Institucionalismo: DiMaggio e Powell(1991). }\end{array}$ \\
\hline A17 & $\begin{array}{l}\text { Ryngelblum } \\
\text { (2007). }\end{array}$ & [Idêntico ao A16] \\
\hline A18 & $\begin{array}{l}\text { Ryngelblum } \\
\text { e Giglio } \\
(2006) \text {. }\end{array}$ & $\begin{array}{l}\text { Modelo das Coalizações Advocatícias: Dudley e Richardson (1999) e Sabatier e } \\
\text { Jenkins-Smith(1999). } \\
\text { Indicações do Institucionalismo TI: DiMaggio e Powell (1991); Meyer e Rowan } \\
\text { (1977) e Zucker, (1983). }\end{array}$ \\
\hline A19 & $\begin{array}{l}\text { Ryngelblum } \\
\text { e Giglio } \\
(2008) \text {. }\end{array}$ & $\begin{array}{l}\text { Experiência na pirataria: Clegg (1990); Bazanini et al. (2006) e Ryngelblum (2005). } \\
\text { Modelo Proposto para a Análise da Pirataria: Ansoff (1965); Porter (1989); Dwyer } \\
\text { et al. (1987); Nohria (1992); Hannan e Freeman (1977); Pfeffer e Salancick (1978); } \\
\text { Freeman (1984); Barney (1991) e Hamel e Prahalad (1994). }\end{array}$ \\
\hline A20 & $\begin{array}{l}\text { Sauerbronn } \\
\text { et al. } \\
(2010) \text {. }\end{array}$ & $\begin{array}{l}\text { Comportamento desviantes de consumo: Becker (1966) e Lima (2001). } \\
\text { Técnicas de Neutralização: Sykes e Matza (1957) e Struton et al. (1994). }\end{array}$ \\
\hline A21 & $\begin{array}{l}\text { Strehlau et } \\
\text { al. }(2014) \text {. }\end{array}$ & $\begin{array}{l}\text { Consumo de Luxo: Czellar e Dubois (2002); Garfein (1989); Berry (1994); Bourdieu } \\
\text { (1979); Featherstone (1995) e Sheth (2001). } \\
\text { Falsificação de marcas: Nill e Schultz II (1996); Zaichkowsky (1995); Collins-Dodd e } \\
\text { Zaichkowsky (1999); Chaudhry (1996); Bush et al. (1989) e Grossman e Shapiro } \\
\text { (1988). }\end{array}$ \\
\hline A22 & $\begin{array}{l}\text { Strehlau e } \\
\text { Peters Filho } \\
(2006) \text {. }\end{array}$ & $\begin{array}{l}\text { Propriedade intelectual: Oberholzer-Gee e Strumpf (2010) e Sinha e Mandel (2008). } \\
\text { Falsificação: Staake, Thiesse e Fleisch (2009); Eisend e Schuchert-Güler (2006); } \\
\text { Bloch, Bush e Campbell (1993); Cordell, Wingtada e Keischnick-Jr (1996); Hennigs, } \\
\text { Wiedmann e Klarmann (2012) e Bagozzi; Gürhan- Canli; Priester (2002). }\end{array}$ \\
\hline A23 & $\begin{array}{l}\text { Trindade } \\
(2008) \text {. }\end{array}$ & $\begin{array}{l}\text { Conceitos de falsificação: Bamossy e Scammon (1985); Chakraborty et al. (1996; } \\
\text { 1997); Baize (1999) e Gentry et al. (2001). } \\
\text { Identidade: Stuart Hall (2005); Gilles e Lipovetsky (2004) e Elias (1994). }\end{array}$ \\
\hline
\end{tabular}

Fonte: desenvolvido pelos autores (2015).

No Quadro 8, tem-se acesso às principais teorias e referências utilizadas nos artigos nacionais. Constata-se que a abordagem dos trabalhos não se resumiu a autores que tratam da falsificação, mas também contemplou teorias ligadas a outras temáticas. É importante destacar que a síntese das teorias de base utilizadas pelos artigos nacionais não objetivou inserir todas as referências citadas nos estudos analisados. Foram utilizadas aquelas consideradas relevantes para a abordagem da teoria.

Como o presente estudo busca facilitar novas pesquisas sobre a temática da falsificação, o Quadro 8 apresenta as principais referências citadas pelos autores de artigos nacionais, para referenciar a falsificação e demais temas relacionados. Observa-se uma ampla gama de autores, principalmente estrangeiros. Além disso, é possível constatar os diversos temas relacionados ao fenômeno da falsificação.

Como mais uma contribuição do mapeamento meta-narrativo, o presente estudo buscou sintetizar as recomendações e limitações dos estudos analisados. O Quadro 9 tem o objetivo de orientar futuros estudos no sentido de explorar as limitações dos estudos já publicados, levando em consideração as recomendações dadas por estes. Destaca-se que os limites e recomendações foram retirados de forma direta dos artigos analisados. Não foram utilizadas, na codificação do Quadro 9, interpretações dos limites e recomendações. Assim, 
em alguns casos, não foi observado limites ou recomendações para futuros estudos, o que não implica que não os tenham.

Quadro 9: Limitações e recomendações para pesquisas

\begin{tabular}{|c|c|c|c|}
\hline Cód. & Ref. & Limitações do estudo & Recomendações \\
\hline A1 & $\begin{array}{l}\text { Alvim et al. } \\
\text { (2013). }\end{array}$ & Inobservado & $\begin{array}{l}\text { Verificar se ainda existem grupos de } \\
\text { release ou courier no consumo de música } \\
\text { pela internet no formato MP3. Também } \\
\text { sugere-se repetir o questionário com uma } \\
\text { amostra composta por diferentes } \\
\text { universidades de regiões diferentes para } \\
\text { avaliar a influência geográfica e a estrutura } \\
\text { de canais de distribuição física disponíveis. }\end{array}$ \\
\hline A2 & $\begin{array}{l}\text { Barros et al. } \\
(2010) \text {. }\end{array}$ & Inobservado & Inobservado \\
\hline A3 & & $\begin{array}{l}\text { Os estudantes constituem amostra } \\
\text { viciada. A situação hipotética pode não } \\
\text { refletir a realidade. O sujeito pode } \\
\text { responder pelo critério político e não } \\
\text { pela sua disposição mental. As histórias } \\
\text { de eventos relacionados a produtos }\end{array}$ & $\begin{array}{l}\text { Pode-se realizar pesquisas observando o } \\
\text { preço como variável de controle. A } \\
\text { pesquisa também pode ser direcionada para } \\
\text { outros públicos (mulheres, adultos, idosos, } \\
\text { desempregados, etc.) para que se possa } \\
\text { comparar os resultados obtidos. }\end{array}$ \\
\hline
\end{tabular}

Bazanini et distinção entre produtos al. (2006). contrabandeados (que são legítimos) e piratas (que são falsos). A palavra pirata foi utilizada de modo indistinto, o que pode ter levado a algumas respostas viesadas. Como ocorre em pesquisas com palavras, podem ocorrer interpretações subjetivas dos sujeitos, que levam a respostas que não poderiam ser comparadas.

A4 Convencionais, associadas ao escopo da amostra e do próprio design da pesquisa.

Casali et al.

(2010).

Explorar, no contexto brasileiro, um
conjunto de outros condicionantes da
prática de pirataria, como aqueles
associados a fatores de restrições de
mercado, inclusive com os potenciais
efeitos da reatância psicológica gerada por
conta da restrição que o consumidor
percebe. Adicionalmente, seria interessante
um estudo que viabilizasse a indicação
mais clara de métodos e opcões de suporte
à práticas de marketing social direcionadas
a alterar o comportamento de potenciais
consumidores de produtos piratas em geral.
Estudos complementares para verificar as
possíveis implicações e o uso de outros
modelos para uma análise mais consistente.
Inobservado
Realização de estudos quantitativos e
qualitativos focando e comparando esse
consumo específico em diferentes classes
sociais, e testando as preferências dos




\begin{tabular}{|c|c|c|c|}
\hline & & & $\begin{array}{l}\text { consumidores por diferentes categorias de } \\
\text { produtos. }\end{array}$ \\
\hline A8 & $\begin{array}{l}\text { Filgueiras e } \\
\text { Silva } \\
(2002) .\end{array}$ & Inobservado & Inobservado \\
\hline A9 & $\begin{array}{l}\text { Giglio e } \\
\text { Ryngelblum } \\
(2009) .\end{array}$ & Inobservado & $\begin{array}{l}\text { O modelo aplicável, inclusive a fenômenos } \\
\text { de redes de negócios que transcendem a } \\
\text { normalidade econômica, sugere uma linha } \\
\text { orientadora para as estratégias de combate, } \\
\text { até então pouco eficiente. }\end{array}$ \\
\hline A10 & $\begin{array}{l}\text { Gomes } \\
\text { Strehlau } \\
(2014) \text {. }\end{array}$ & Inobservado & $\begin{array}{l}\text { Nota-se que existem na elaboração mental } \\
\text { do consumidor duas categorias distintas o } \\
\text { falso e o verdadeiro. O trabalho de } \\
\text { marketing que vise diminuir este tipo de } \\
\text { consumo tem que ser mais dirigido para o } \\
\text { consumidor de produtos falsificados que } \\
\text { apresenta uma regra heurística diferente } \\
\text { daquele que prefere comprar somente os } \\
\text { originais. }\end{array}$ \\
\hline A11 & $\begin{array}{l}\text { Grohmann } \\
(2015) \text {. }\end{array}$ & $\begin{array}{l}\text { A amostra ser formada apenas por } \\
\text { jovens estudantes e o constructo justiça } \\
\text { apresentar carência de estudos, tanto em } \\
\text { nível nacional como internacional, no } \\
\text { campo do comportamento do } \\
\text { consumidor. }\end{array}$ & $\begin{array}{l}\text { Ampliação de estudos voltados para a } \\
\text { questão da justiça como elemento que } \\
\text { influencia o consumo. Outra sugestão se } \\
\text { refere ao acréscimo de construtos que } \\
\text { podem auxiliar na explicação do uso de } \\
\text { softwares piratas. }\end{array}$ \\
\hline A12 & $\begin{array}{l}\text { Machado } \\
(2012)\end{array}$ & $\begin{array}{l}\text { Segmento de } \text { mercado limitado, } \\
\text { representado } \\
\text { multinacionais } \\
\text { medicamentos de disfunção erétil, que } \\
\text { tem peculiaridades distintas. }\end{array}$ & $\begin{array}{l}\text { Estender o estudo para outros segmentos, } \\
\text { principalmente para as estratégias de não- } \\
\text { mercado, já que as instituições } \\
\text { governamentais são praticamente as } \\
\text { mesmas. }\end{array}$ \\
\hline A13 & $\begin{array}{l}\text { Machado } \\
\text { Bazuchi } \\
(2012) .\end{array}$ & [Idêntico ao A12] & [Idêntico ao A12] \\
\hline A14 & $\begin{array}{l}\text { Machado } \\
\text { Mello } \\
(2013) .\end{array}$ & [Idêntico ao A12] & [Idêntico ao A12] \\
\hline A15 & $\begin{array}{l}\text { Matos } \\
\text { Ituassu } \\
(2005) .\end{array}$ & $\begin{array}{l}\text { Fato de não ter sido investigada } \\
\text { nenhuma categoria específica de } \\
\text { produtos piratas (ex. CDs, DVDs, } \\
\text { roupas, acessórios, brinquedos, } \\
\text { eletrônicos etc.). A amostra estudada foi } \\
\text { do tipo não probabilística. }\end{array}$ & $\begin{array}{l}\text { Estender a pesquisa para outras regiões e } \\
\text { cidades. Investigar também categorias } \\
\text { específicas de produtos piratas como CDs, } \\
\text { DVDs, roupas, acessórios, brinquedos, } \\
\text { eletrônicos, etc. }\end{array}$ \\
\hline A16 & $\begin{array}{l}\text { Ryngelblum } \\
(2005) \text {. }\end{array}$ & Inobservado & Inobservado \\
\hline A17 & $\begin{array}{l}\text { Ryngelblum } \\
(2007) \text {. }\end{array}$ & Inobservado & Inobservado \\
\hline A18 & $\begin{array}{l}\text { Ryngelblum } \\
\text { e Giglio } \\
(2006) \text {. }\end{array}$ & Inobservado & $\begin{array}{l}\text { Pesquisar um maior número de } \\
\text { respondentes de outros órgãos, a fim de } \\
\text { aprofundar as informações e conhecimento } \\
\text { do tratamento governamental. Aprofundar } \\
\text { o conhecimento a respeito das variáveis do } \\
\text { modelo. Entender em maior profundidade } \\
\text { os valores dos atores envolvidos. }\end{array}$ \\
\hline A19 & $\begin{array}{l}\text { Ryngelblum } \\
\text { e Giglio } \\
(2008) \text {. }\end{array}$ & $\begin{array}{l}\text { A limitação sugerida é que nem sempre } \\
\text { uma ação pode ser claramente } \\
\text { identificada como a proposta pelo } \\
\text { estudo. É comum que no seu desenrolar } \\
\text { ela possa assumir diferentes caráteres. A } \\
\text { análise é feita a partir de uma } \\
\text { simplificação empírica. }\end{array}$ & $\begin{array}{l}\text { Acompanhamento da implementação do } \\
\text { plano e da eficácia de suas ações. }\end{array}$ \\
\hline
\end{tabular}




\begin{tabular}{|c|c|c|c|}
\hline $\mathrm{A} 20$ & $\begin{array}{l}\text { Sauerbronn } \\
\text { et al. } \\
(2010) \text {. }\end{array}$ & Inobservado. & $\begin{array}{l}\text { Analisar outros comportamentos desviantes } \\
\text { que podem ser analisados a partir da } \\
\text { técnica utilizada. }\end{array}$ \\
\hline A21 & $\begin{array}{l}\text { Strehlau et } \\
\text { al. }(2014) \text {. }\end{array}$ & $\begin{array}{l}\text { Considera-se que a perspectiva adotada } \\
\text { no estudo envolve interpretação e } \\
\text { julgamento de valor. }\end{array}$ & $\begin{array}{l}\text { Abordar a questão por meio da observação } \\
\text { participante, examinando-a junto aos } \\
\text { vendedores e lojas. }\end{array}$ \\
\hline A22 & $\begin{array}{l}\text { Strehlau e } \\
\text { Peters Filho } \\
(2006) \text {. }\end{array}$ & [Idêntico ao A21] & $\begin{array}{l}\text { Abordar a questão por meio da observação } \\
\text { participante, examinando-a junto aos } \\
\text { vendedores e lojas. Seria interessante } \\
\text { adicionar uma análise da perda da noção do } \\
\text { tempo quando o indivíduo quer tudo ao } \\
\text { mesmo tempo e imediatamente. }\end{array}$ \\
\hline A23 & $\begin{array}{l}\text { Trindade } \\
\text { (2008). }\end{array}$ & Inobservado & Inobservado \\
\hline
\end{tabular}

Fonte: desenvolvido pelos autores (2015).

Destaca-se que muitos trabalhos não mencionaram as limitações dos mesmos. Isso não implica que os autores tenham desconsiderado as limitações dos estudos, apenas não foram identificadas na análise sistemática. Em resumo, as limitações se dão pela amostra pesquisada, teorias de base utilizadas e objeto estudado. As recomendações para futuras pesquisas se voltam para a adoção de amostras probabilísticas, uso de outros métodos de análise de dados, melhor heterogeneidade da amostra e acompanhamento e monitoramento do objeto de estudo.

Por fim, baseando-se na estrutura sugerida por Petticrew e Roberts (2006), revisou-se as principais contribuições dos artigos, que podem ser observadas no Quadro 10. Destaca-se que as contribuições do estudo foram retiradas dos artigos analisados. Buscou-se reduzir a interferência subjetiva dos autores do presente artigo, atendo-se ao máximo às ideias dos pesquisadores originais.

Quadro 10: Contribuições do estudo

\begin{tabular}{|c|c|c|}
\hline Cód. & Ref. & Contribuições do estudo \\
\hline A1 & $\begin{array}{l}\text { Alvim et al. } \\
\text { (2013). }\end{array}$ & $\begin{array}{l}\text { Entender o consumidor de música pirata consoante ao desenvolvimento de estratégias } \\
\text { mercadológicas para a migração do consumidor 'ilegal' para o consumidor legal. }\end{array}$ \\
\hline $\mathrm{A} 2$ & $\begin{array}{l}\text { Barros et al. } \\
(2010) \text {. }\end{array}$ & $\begin{array}{l}\text { Contribui para o entendimento do consumidor de músicas digitais sobre a prática da } \\
\text { pirataria de música. }\end{array}$ \\
\hline A3 & $\begin{array}{l}\text { Bazanini et } \\
\text { al. (2006). }\end{array}$ & $\begin{array}{l}\text { Sugere que as políticas de combate não sejam centradas no preço, pois a intenção de } \\
\text { compra de produtos falsificados decorre de alterações nos processos normais e ideias do } \\
\text { levantamento e decisão de alternativas. }\end{array}$ \\
\hline A4 & $\begin{array}{l}\text { Casali et al. } \\
(2010) \text {. }\end{array}$ & $\begin{array}{l}\text { Percepção de custo pelo consumidor de softwares praticamente não exerce influências } \\
\text { sobre o comportamento do consumidor. No entanto, foi observado que a dimensão } \\
\text { moral apresenta efetivo condicionamento sobre a pirataria de software. }\end{array}$ \\
\hline A5 & $\begin{array}{l}\text { Casali } \\
\text { Costa } \\
(2014)\end{array}$ & $\begin{array}{l}\text { Os resultados sugerem que o consumidor apresenta de uma forma geral uma tendência } \\
\text { ao comportamento ético, embora em questões associadas à pirataria de software não } \\
\text { haja uma tendência clara quanto à percepção de eticalidade envolvida. }\end{array}$ \\
\hline A6 & $\begin{array}{l}\text { Costa } \\
(2001)\end{array}$ & $\begin{array}{l}\text { O mosaico de leis que pode envolver a Internet implica uma concepção jurídica nova a } \\
\text { ser delineada para acompanhar as novas regras do jogo. Até que isso aconteça, porém, } \\
\text { continuarão a ser aplicados os conceitos e modelos tradicionais do Direito, consoantes } \\
\text { ao mercado de produtos falsificados. }\end{array}$ \\
\hline A7 & $\begin{array}{l}\text { Costa e } \\
\text { Sant'Anna } \\
(2008)\end{array}$ & $\begin{array}{l}\text { Identificou elementos recorrentes ao comportamento dos consumidores de produtos } \\
\text { falsificados. O estudo possibilitou perceber que para o grupo estudado a aquisição de } \\
\text { produtos falsificados ou piratas configura-se como uma prática aceitável e moralmente } \\
\text { válida. }\end{array}$ \\
\hline
\end{tabular}

REAd | Porto Alegre - Edição 86 - Nº 2 - Maio / Agosto 2017 - p. 135 - 166 


\begin{tabular}{|c|c|c|}
\hline A8 & $\begin{array}{l}\text { Filgueiras e } \\
\text { Silva } \\
(2002)\end{array}$ & $\begin{array}{l}\text { Verificou-se que a indústria fonográfica pode estar sendo ameaçada pelos seguintes } \\
\text { fatores: a concorrência com a pirataria crescente; a possível substituição pelo } \\
\text { intercâmbio gratuito de MP3 via Internet; a ambiguidade estratégica de várias } \\
\text { gravadoras; a ausência de marketing de marca, bem como do relacionamento com } \\
\text { consumidores finais e artistas; e o absoluto desconhecimento a respeito de como os CDs } \\
\text { são atualmente consumidos. }\end{array}$ \\
\hline A9 & $\begin{array}{l}\text { Giglio e } \\
\text { Ryngelblum } \\
(2009) \text {. }\end{array}$ & $\begin{array}{l}\text { Sugere-se a presença de representações sociais positivas sobre a ponta da pirataria, que é } \\
\text { o camelô, e representações sociais negativas sobre o governo e as empresas que } \\
\text { combatem a ilegalidade. }\end{array}$ \\
\hline A10 & $\begin{array}{l}\text { Gomes e } \\
\text { Strehlau } \\
(2014) \text {. }\end{array}$ & $\begin{array}{l}\text { Embora a proteção solar nos óculos seja extremamente importante, é em quantidade } \\
\text { numericamente inferior aos atributos oriundos da marca como design e moda e o } \\
\text { atributo físico da cor da lente, resultando assim, na compra de óculos pirata. }\end{array}$ \\
\hline A11 & $\begin{array}{l}\text { Grohmann } \\
(2015) \text {. }\end{array}$ & $\begin{array}{l}\text { Os resultados demonstraram que: justiça recíproca e justiça processual influenciam } \\
\text { significativamente a atitude e a intenção de uso de softwares piratas; e a norma subjetiva } \\
\text { impacta na atitude. }\end{array}$ \\
\hline A12 & $\begin{array}{l}\text { Machado } \\
(2012) \text {. }\end{array}$ & $\begin{array}{l}\text { As empresas farmacêuticas que sofrem maior impacto com a pirataria se estruturam na } \\
\text { relação matriz-subsidiária no formato geocêntrico com estratégias de não-mercado } \\
\text { globais, e localmente estas empresas optam pelas atividades coletivas independente dos } \\
\text { recursos disponíveis. }\end{array}$ \\
\hline A13 & $\begin{array}{l}\text { Machado e } \\
\text { Bazuchi } \\
\text { (2012). }\end{array}$ & $\begin{array}{l}\text { Em relação à estrutura organizacional das indústrias farmacêuticas multinacionais, nota- } \\
\text { se que a complexidade e as contínuas mudanças que ocorrem no governo brasileiro, e } \\
\text { dentro das próprias instituições, ocasionam transformações importantes. Assim, a } \\
\text { literatura prevê que a estratégia global de não-mercado (pirataria) não tem o mesmo } \\
\text { sucesso das estratégias de mercado, pois precisam levar em conta as instituições, as } \\
\text { questões políticas e as configurações existentes nos países onde as empresas estão } \\
\text { localizadas. }\end{array}$ \\
\hline A14 & $\begin{array}{l}\text { Machado } \\
\text { Mello } \\
(2013)\end{array}$ & $\begin{array}{l}\text { Países onde seus gerentes percebem um alto nível de pirataria de produtos } \\
\text { farmacêuticos de disfunção erétil adotam ações tailor-made diferenciadas por país; ou } \\
\text { seja, a gestão do combate à pirataria nas empresas farmacêuticas é centralizada, com } \\
\text { pouca autonomia local e com pouca integração com as atividades de mercado. }\end{array}$ \\
\hline A15 & $\begin{array}{l}\text { Matos } \\
\text { Ituassu } \\
(2005)\end{array}$ & $\begin{array}{l}\text { Os resultados mostraram que as variáveis norma subjetiva, risco percebido e o fato de já } \\
\text { ter comprado ou não um produto pirata influencia significativamente as atitudes do } \\
\text { consumidor em relação a esses produtos. De forma similar, as intenções } \\
\text { comportamentais desses consumidores são também afetadas por essas variáveis, } \\
\text { juntamente com as atitudes. }\end{array}$ \\
\hline A16 & $\begin{array}{l}\text { Ryngelblum } \\
(2005) \text {. }\end{array}$ & $\begin{array}{l}\text { Constatou-se que as empresas evitam utilizar seu instrumental tradicional contra a } \\
\text { pirataria, recorrendo sobretudo a ações delegadas para tentar parar ou eliminar os efeitos } \\
\text { trazidos pelo mercado ilegal. Por outro lado, elas abdicam de uma associação mais } \\
\text { efetiva com esses atores delegados, submetendo-se totalmente aos objetivos e métodos } \\
\text { destes últimos. }\end{array}$ \\
\hline A17 & $\begin{array}{l}\text { Ryngelblum } \\
\text { (2007). }\end{array}$ & $\begin{array}{l}\text { A estratégia empresarial deve abandonar os modelos que partem do pressuposto da } \\
\text { autossuficiência, do esforço isolado e do planejamento apriorístico, para adotar uma } \\
\text { opção por parcerias específicas, que se encontram nesse caso fora de seu meio-ambiente } \\
\text { tecno-econômico, mas que dividem com esta um interesse comum. }\end{array}$ \\
\hline A18 & $\begin{array}{l}\text { Ryngelblum } \\
\text { e Giglio } \\
(2006) \text {. }\end{array}$ & $\begin{array}{l}\text { Os resultados obtidos permitem avaliar que várias das restrições institucionais mais } \\
\text { arraigadas, que ajudam a sedimentar a pirataria não estão sendo combatidas } \\
\text { suficientemente pelas políticas públicas praticadas, havendo ênfase, como seria de se } \\
\text { esperar, em práticas tradicionais. Falta sobretudo capacidade para legitimar as ações que } \\
\text { são implementadas. }\end{array}$ \\
\hline A19 & $\begin{array}{l}\text { Ryngelblum } \\
\text { e Giglio } \\
(2008) \text {. }\end{array}$ & $\begin{array}{l}\text { O Plano Nacional de Combate à Pirataria deverá enfrentar dificuldades para dar certo, } \\
\text { uma vez que este consiste principalmente na continuidade de práticas anteriores, } \\
\text { mormente no que tange às práticas repressivas, que já constituíam o núcleo das ações } \\
\text { conduzidas até aqui. Algumas das práticas socioculturais associadas à questão da } \\
\text { pirataria, que permitem a continuidade do problema, como a corrupção, não são } \\
\text { abordadas diretamente pelo plano. }\end{array}$ \\
\hline A 20 & $\begin{array}{l}\text { Sauerbronn } \\
\text { et al. } \\
(2010) \text {. }\end{array}$ & $\begin{array}{l}\text { O artigo observa } 8 \text { justificativas para o consumo de downloads ilegais, são eles: } \\
\text { Negação do Comportamento Desviante; Ausência de Ganho; Insignificância do } \\
\text { Prejuízo; Inversão; Justiça; Incapacidade; Hipocrisia e Direito de Acesso à Cultura. }\end{array}$ \\
\hline A 21 & $\begin{array}{l}\text { Strehlau et } \\
\text { al. }(2014) .\end{array}$ & $\begin{array}{l}\text { O estudo revelou que a marca falsificada tem valor para o cliente por meio de apelos } \\
\text { sociais e econômicos. Para tal é necessário não pretender passar o falso por verdadeiro, }\end{array}$ \\
\hline
\end{tabular}

REAd | Porto Alegre - Edição 86 - Nº 2 - Maio / Agosto 2017 - p. 135 - 166 


\begin{tabular}{lll}
\hline & & $\begin{array}{l}\text { à medida em que o risco social de ser desmascarado é transformado em experiência } \\
\text { prestigiosa ao possibilitar a exibição de conhecimentos sobre a marca original, } \\
\text { comentários sobre viagens ao exterior, ou exibição de um perfil de comprador esperto. }\end{array}$ \\
\hline A22 & $\begin{array}{l}\text { Strehlau e e } \begin{array}{l}\text { Peters Filho } \\
(2006) .\end{array} \\
\text { Um novo construto constituído por itens das escalas de prontidão e de atitude foi } \\
\text { identificado Atitudes de Prontidão de Compra de Falsificações (APCF) e mostrou } \\
\text { capacidade preditiva em relação às compras passadas e à intenção de compra. Contribui } \\
\text { para o conhecimento acerca de fatores previsores do consumo de produtos falsificados. }\end{array}$ \\
\hline A23 & $\begin{array}{l}\text { Trindade } \\
(2008) .\end{array}$ & Evidencia a alta valorização do olhar do outro e uma nova lógica do efeito trickle-down. \\
\hline
\end{tabular}

Fonte: desenvolvido pelos autores (2015).

A identificação das contribuições dos estudos, por meio de fragmentos textuais dispostos no Quadro 10, não teve o objetivo de sistematizar todas as contribuições empíricas e teóricas, mas sintetizar algumas e buscar avançar no entendimento do fenômeno, observando a individualidade de cada produção. Observa-se que, apesar das relevantes contribuições dispostas no Quadro 10, elas se limitam ao entendimento sob a perspectiva da demanda por produtos falsificados.

\subsection{Dissertações e tese: mapeamento meta-narrativo}

As dissertações foram analisadas iniciando pelos aspectos gerais das publicações. Em relação às teses, foi encontrada somente uma na área de Administração. Ressalta-se que há outras teses defendidas no Brasil ${ }^{1}$, abordando a mesma temática, mas foram defendidas em programas distintos ao da área de Administração.

O Quadro 11 apresenta as dissertações e tese defendidas de acordo com o Programa de Pós-Graduação em Administração (PPGA). Com isso, objeta-se identificar os programas que promovem pesquisas para entendimento do fenômeno.

Quadro 11: Instituição de Ensino

\begin{tabular}{r|l}
\hline \multicolumn{1}{c|}{ Código } & IES \\
\hline D5, D8, D9, D11 e T1 & Fundação Getúlio Vargas de São Paulo (FGV/SP) \\
\hline D2, D6 e D12 & Fundação Getúlio Vargas do Rio de Janeiro (FGV/RJ) \\
\hline D1 e D7 & Universidade Federal da Paraíba (UFPB) \\
\hline D10 e D13 & Universidade Federal do Rio Grande do Sul (UFGRS) \\
\hline D3 & Universidade de São Paulo (USP) \\
\hline D4 & Faculdades Integradas de Pedro Leopoldo/MG \\
\hline
\end{tabular}

Fonte: desenvolvido pelos autores (2015).

Os PPGAs com maior número de dissertações analisadas são a Fundação Getúlio Vargas de São Paulo e do Rio de Janeiro. Em termos proporcionais, os PPGAs de

\footnotetext{
1 Exemplos: Direto: IOKOI, P. A apreensão no procedimento dos crimes contra a propriedade imaterial. Universidade de São Paulo, 2013. Antropologia Social: PINHEIRO-MACHADO, R. Made in China: produção e circulação de mercadorias no circuito China-Paraguai-Brasil. Universidade Federal do Rio Grande do Sul, 2009. Sociologia: LADEIRA, A. G. O Bom Gosto Pelas Margens: motivações sociais no consumo de produtos piratas. Universidade Federal de Minas Gerais, 2013.
} 
universidades públicas dispunham de cinco dissertações no momento da pesquisa, enquanto as instituições privadas somavam oito dissertações e uma tese.

Os objetos de estudos das dissertações e tese consideraram temas distintos dos artigos. Observa-se, no Quadro 12, que três dissertações analisadas investigaram o consumo de falsificados sem caracterizar um item específico.

Quadro 12: Objeto de estudo

\begin{tabular}{r|l}
\hline \multicolumn{1}{c|}{ Código } & \multicolumn{1}{c}{ Objetos de estudo } \\
\hline D5, D6, D10 e D12 & Indústria fonográfica \\
\hline D2, D11 e D13 & Consumo geral de falsificados (não há um item específico) \\
\hline D3, D9 e T1 & Produtos de luxo \\
\hline D8 & Indústria farmacêutica \\
\hline D7 & Jogos digitais \\
\hline D4 & Roupas e acessórios \\
\hline D1 & Software \\
\hline
\end{tabular}

Fonte: desenvolvido pelos autores (2015).

Foi observado um maior número de trabalhados relacionados à indústria fonográfica. No entanto, ao contrário do que se observou nos artigos, as dissertações não exploraram o mercado digital como objeto de estudo.

Assim como se observou nos artigos analisados, as dissertações e tese também apresentaram maior quantidade de estudos que abordavam a demanda de produtos falsificados, como pode-se observar no Quadro 13.

Quadro 13: Recorte da pesquisa

\begin{aligned} & \multicolumn{1}{c}{ Código } Recorte da pesquisa \\ & \hline $\mathrm{D} 1, \mathrm{D} 2, \mathrm{D} 3, \mathrm{D} 4, \mathrm{D} 5, \mathrm{D} 7, \mathrm{D} 9, \mathrm{D} 10, \mathrm{D} 11, \mathrm{D} 12, \mathrm{D} 13$ e T1 Consumo de produtos falsificados (demanda). \\ & \hline D6 e D8 Concorrência entre organizações legítimas e ilegais \\ & \hline\end{aligned}

Fonte: desenvolvido pelos autores (2015).

Nesse sentido, acredita-se que trabalhos que abordem a oferta de produtos falsificados poderiam agregar relevantes contribuições ao campo de estudo. Investigar a produção, ou seja, a oferta de itens falsificados, poderia ampliar a compreensão do fenômeno sob uma outra perspectiva.

A análise dos aspectos metodológicos das dissertações e tese iniciou pela natureza de pesquisa. Diferentemente dos artigos, as dissertações e tese apresentaram certa equidade entre pesquisas de natureza qualitativa e quantitativa, como se observa no Quadro 14.

Quadro 14: Natureza da pesquisa

\begin{tabular}{r|l}
\hline \multicolumn{1}{c|}{ Código } & Natureza da pesquisa \\
\hline D2, D5, D6, D8, D9, D13 eT1 & Qualitativa \\
\hline D1, D3, D7, D10, D11 & Quantitativa \\
\hline D4 e D12 & Qualitativa e Quantitativa \\
\hline
\end{tabular}

REAd | Porto Alegre - Edição 86 - No 2 - Maio / Agosto 2017 - p. 135 - 166 
Fonte: desenvolvido pelos autores (2015).

Duas dissertações se basearam em pesquisas de natureza qualitativa e quantitativa para entendimento do fenômeno. É importante destacar que a metodologia não se limita à natureza de pesquisa. Assim, os Quadros 16 e 17 buscam aprofundar a análise metodológica dos estudos analisados.

O Quadro 15 demonstra que, em relação ao método de coleta da pesquisa, o mais utilizado foi o levantamento, empregado por todas as dissertações de natureza quantitativa. As dissertações de natureza qualitativa utilizaram tanto a entrevista em profundidade como a entrevista semiestruturada, por meio de roteiro de entrevista.

\begin{tabular}{r|c}
\multicolumn{2}{c}{ Quadro 15: Coleta de dados } \\
\hline Código & Coleta de dados \\
\hline D2, D5, D12, D13 e T1 & Entrevista em profundidade com roteiro \\
\hline D4, D6, D8 e D9 & Entrevista semiestruturada com roteiro \\
\hline D1, D3, D4, D7, D10, D11 e D12 & Levantamento (survey) \\
\hline Fonte: desenvolvido pelos autores (2015).
\end{tabular}

Como se observa no Quadro 16, todas as dissertações de natureza qualitativa analisadas utilizaram a análise de conteúdo, enquanto a tese utilizou da analise do discurso.

Quadro 16: Método para análise de dados

\begin{tabular}{r|l}
\multicolumn{1}{c|}{ Código } & \multicolumn{1}{c}{ Método de análise dos dados } \\
\hline D2, D4, D5, D6, D8, D9, D12 e D13 & Análise de conteúdo \\
\hline D7 e D11 & Análise de variância \\
\hline D1 e D3 & Análise univariada \\
\hline D7 & Análise fatorial \\
\hline D1 & Análise bivariada \\
\hline D12 & Regressão linear múltipla \\
\hline D10 & Regressão logística \\
\hline T1 & Análise do discurso \\
\hline
\end{tabular}

Fonte: desenvolvido pelos autores (2015).

Já nas dissertações de natureza quantitativa, foi observada a utilização de diversos métodos para a análise dos dados. É importante destacar que na dissertação D4 não se observou qual método para a análise de dados quantitativos foi empregado. Assim como os artigos, as dissertações de natureza qualitativa utilizaram mais de um instrumento para a obtenção dos dados.

Os conceitos e teorias de base utilizados nas dissertações foram abrangentes e, como esperado, apresentaram maior profundidade do que os artigos, o que pode ser explicado pelo limite de páginas exigido pelos eventos e periódicos.

As dissertações conseguiram, em alguns casos, evoluir a discussão teórica de forma mais aprofundada, para sustentação dos objetivos de pesquisa. O Quadro 17 elenca os 
principais autores utilizados como referências para os conceitos e teorias empregados nas dissertações e tese.

Quadro 17: Dissertações: teorias de base e referências

\begin{tabular}{ll} 
Código & \multicolumn{1}{c}{ Teorias de basee referências } \\
\hline & Fundamentos gerais de ética: Chauí (2008); Ferrel, Gresham e Fraedrich (1989); Costa (2003); \\
& Vitell, Sighapakdi e Thomas (2001) e Hunt e Vitell (1986). \\
& Ética e marketing: Malhotra e Miller (1998); Nill e Schibrowsky (2007); Bartels (1988); \\
& Manuera (1992); Kerin (1996); Wilkie e Moore (2003); Kotler (1969; 1972), Bagozzi (1975); \\
& Laytone Grossbart (2006); Schlegelmilch e Öberseder (2009); Nill e Schibrovsky (2007); Jones \\
D1 & (1991); Vitell, Singhapakdi e Thomas (2001) e Shang, Chen e Chen (2008).
\end{tabular}

Casali Responsabilidade social do consumidor: Vitell e Paolillo (2003); Steenhaut e Kenhove (2006);

(2011) Shang, Chen e Chen (2008); Rawwas, Swaidan e Isakson (2007); Brinkmann e Peattie (2008); D"Astous e Legendre (2009); François-Lecompte e Roberts (2006); Leigh, Murphy e Enis (1988) e Queiroga et al. (2005).

Pirataria de software: Orrico Júnior (2004); Peitz e Waelbroeck (2006); Nill e Shultz II (2009); Mason(1986); Peace, Galletta e Thong (2003); Phau e Ng(2009); Hinduja (2003) e Peace, Galletta e Thong (2003).

Valor, conceitos e perspectivas: Douglas e Isherwood (2004); Goodman e Cohen (2004);

D2 Arnould, Price e Zinkhan (2005); Bevan e Murphy (2001); Graeber (2005); Holbrook(1999);

Ferreira Kotler (2000); Veludo-de-Oliveira e Ikeda (2005) e Campbell (2001).

(2007) Falsificados: Ordell, Wongtada e Kieschnick (1996); Gentry et al. (2001); Penz e Stöttinger (2005); Gentry, Putrevu e Shultz (2006); McCracken (2003); Strehlau (2005); Ferreira, Botelho e Almeida (2008) e Belk, Devinney e Eckhardt (2005).

D3 Mercado de luxo: Strehlau (2004); Lipovesty e Roux (2005); Gatard (1991); Serraf (1991);

Galhanone D’Angelo (2006); Allérès (1999);Rigby e D’Arpizio (2007); Twitchell (2002); Solomon (2002);

(2008) Mccracken (1990); Campbell (1995); Kotler e Keller (2006); Belk et al. (2003); Schiffman e Kanuk (1997) e Kotler e Armstrong (2003).

D4 et al. (1995); Kotler (2000); Featherstone (1995); Schiffman e Kanuk (1997); Sheth et al. (2001);

Junqueira André (2006); Bauman (2008); McCracken (2003); Porto e Porto (2006) e Sant'Anna(2009).

(2012) Falsificado: O'Dougherty (2002); Ferreira (2008); Strehlau (2004); Tavares (2007) e Leitão et al. (2006).

\begin{tabular}{|c|c|}
\hline $\begin{array}{c}\text { D5 } \\
\text { Kikko } \\
(2012)\end{array}$ & $\begin{array}{l}\text { Mercado fonográfico: Vogel (2011); Taintor (2004); Pikas, Pikas, e Lymburner (2011) e } \\
\text { Ortellado (2010). }\end{array}$ \\
\hline $\begin{array}{c}\text { D6 } \\
\text { Lannes } \\
(2009)\end{array}$ & $\begin{array}{l}\text { Iercado fonográfico e inovação: Schumpeter (1911); Charitou e Markides (2003) e Christensen } \\
\text { Overdorf (2000). }\end{array}$ \\
\hline $\begin{array}{c}\text { D7 } \\
\text { Leite } \\
(2012)\end{array}$ & $\begin{array}{l}\text { larketing e ética: Kotler (1972); Hunt e Vitell (2006); Wilkie e Moore (2007); Chaú́ (2000); } \\
\text { asali(2011); Uusitalo e Oksanen (2004); Dodge } \text { et al. (1996); Mohr } \text { et al. (2008); Belk (1995); } \\
\text { ichins e Dawson (1992); } \\
\text { irataria: Jacobs } \text { et al. (2001); Savona e Mignone (2004); Gupta } \text { et al. (2004) e Nobuya (2011). }\end{array}$ \\
\hline $\begin{array}{c}\text { D8 } \\
\text { Machado } \\
\text { (2011) }\end{array}$ & $\begin{array}{l}\text { Estratégias institucionais: North (1990); Peng (2008); Pearce (2001); Boddewyn (2003); Baron } \\
\text { (2003) e Hillman e Hitt (1999). }\end{array}$ \\
\hline $\begin{array}{c}\text { D9 } \\
\text { Martins } \\
(2009)\end{array}$ & $\begin{array}{l}\text { Mercado de luxo: Dubois e Laurent (1996); Allérès (2000); Ciaffone (2007); Kapferer (2003); } \\
\text { Weillbacher (1995); Kleiber (1990); Webster (2002); Tungate (2005); Chevalier e Mazzalovo } \\
\text { (2008); Bastien e Kapferer (2008); Cauduro (2004); Aaker e Joachimsthaler (2000); Reynolds e } \\
\text { Gutman (1984) e Strehlau (2003). }\end{array}$ \\
\hline $\begin{array}{c}\text { D10 } \\
\text { Martins } \\
(2012)\end{array}$ & $\begin{array}{l}\text { Comportamento do consumidor: Makkonen et al. (2011); Plowman (2009); Styvén (2007); } \\
\text { Kotler (2000); Blackwell et al. (2009) e Mittal (2010). }\end{array}$ \\
\hline $\begin{array}{c}\text { D11 } \\
\text { Ribeiro } \\
\text { (2015) }\end{array}$ & $\begin{array}{l}\text { Vergonha: Belk (1988); Lewis (2003); Sauerbronn et al. (2005); Verbeke e Bagozzi (2002) e } \\
\text { Fraedrich e Farrell (1992). } \\
\text { Falsificado: Chaudhry e Stumpf (2011); Staake et al. (2009); Kim et al. (2009); Lai e } \\
\text { Zaichkowsky (1999); Gentry, Putrevu, Shultz e Commuri (2001) e Wilcox et al. (2009). }\end{array}$ \\
\hline D12 & Mercado fonográfico: Fraunhofer (2008); Araujo et al. (2007); Gonçalves (2007); Monteiro \\
\hline
\end{tabular}

REAd | Porto Alegre - Edição 86 - No 2 - Maio / Agosto 2017 - p. 135 - 166 


\begin{tabular}{|c|c|}
\hline $\begin{array}{l}\text { Santos } \\
\text { Junior } \\
(2009)\end{array}$ & (2007) e Lacher e Mizerski (1994). \\
\hline $\begin{array}{l}\text { D13 } \\
\text { Vieira } \\
(2006)\end{array}$ & $\begin{array}{l}\text { Consumo: Fisk (1973); Webster (1975); Kolmuss e Agyeman (2002); Campbell (2000); Albers- } \\
\text { Miller (1999); Wee, Tan e Chouk(1995); Tom et al. (1998); Fitchett e Smith (2002); } \\
\text { O’shaughnessy e O’shaughnessy (2002) e Burroughs e Rindfleisch (2002). }\end{array}$ \\
\hline $\begin{array}{l}\text { T1 } \\
\text { Strehlau } \\
(2004)\end{array}$ & $\begin{array}{l}\text { Produtos e marcas de luxo: Czellar e Dubois (2002); Varian (2000); McKendrick (1982); } \\
\text { Featherstone (1995); Bourdieu (1979); Taschner (1996, } 97 \text { e 2000); Kapferer (1992 e 2003); } \\
\text { Herlory et al. (2002); Kotler (2000); Dubois e Duquesne (1993); Neiestz (1991); Allérès (2000); } \\
\text { Keller (1998); Aaker (1991 e 1996); Solomon (1992); Vigneron (1999); Roux (1991); Vigneron e } \\
\text { Johnson (1999) e Zaichkowsky (1995). } \\
\text { Produtos e marcas falsificadas: Bamossy e Scammon (1985); Grossman e Shapiro (1988a } \\
\text { e1988b); Chaudhry (1996); Chakraborty et al. (1996 e 1997); Baize (1999); Zaichkowsky (1995); } \\
\text { Delener (2000); Gentry et al. (2001); Nill e Schultz II (1996); Nia e Zaichkowsky (2000); Bloch } \\
\text { (1993) e Wee, Tan e Cheok (1995). } \\
\text { Comportamento do consumidor de luxo: Engel, Blackwell e Miniard (1995); Leibenstein } \\
\text { (1950); Bearden e Etzel (2001); Salomon (1996); Allen (1994); Rocha et al. (1999); Taschner } \\
\text { (1996, 1997) e Bourdieu (1989). }\end{array}$ \\
\hline
\end{tabular}

Fonte: desenvolvido pelos autores (2015).

A apresentação das teorias de base e principais referências não teve o objetivo de coletar todos os conceitos e referências utilizados pelos pesquisadores. Foram elencados os principais autores utilizados para a sustentação teórica das dissertações e tese. Nesse sentido, percebe-se um amplo espectro de autores e correntes teóricas utilizadas nos estudos.

Os limites que podem ser explorados por novas pesquisas, bem como as recomendações das dissertações e tese foram organizados no Quadro 18. Observa-se que as principais limitações dos estudos se dão na escolha metodológica, principalmente relacionada à amostra de pesquisa.

Quadro 18: Dissertações: limites e recomendações para pesquisas

\begin{tabular}{|c|c|c|}
\hline Código & Limites do estudo & Recomendações \\
\hline $\begin{array}{c}\text { D1 } \\
\text { Casali } \\
(2011)\end{array}$ & $\begin{array}{l}\text { O fato da amostragem utilizada ser não } \\
\text { probabilística impede a generalização dos } \\
\text { resultados. Em termos teóricos, entende-se } \\
\text { que a seleção da pirataria de software } \\
\text { como contexto o teste empírico da escala } \\
\text { RSCons representou uma limitação. }\end{array}$ & $\begin{array}{l}\text { Investigar e aplicar o modelo a partir de } \\
\text { segmentações socioeconômicas e demográficas, } \\
\text { para melhor entendimento das variações e dos } \\
\text { fatores que fazem com que alguns consumidores se } \\
\text { comportem de maneira mais socialmente } \\
\text { responsável ou de forma mais eticamente } \\
\text { apropriada que outros. }\end{array}$ \\
\hline $\begin{array}{c}\text { D2 } \\
\text { Ferreira } \\
(2007)\end{array}$ & $\begin{array}{l}\text { Limitações próprias do método e } \\
\text { limitações da análise de dados. }\end{array}$ & Inobservado. \\
\hline $\begin{array}{c}\text { D3 } \\
\text { Galhanone } \\
(2008)\end{array}$ & $\begin{array}{l}\text { A amostra utilizada como base para as } \\
\text { análises da pesquisa empírica não permite } \\
\text { generalizações dos achados para a } \\
\text { população brasileira. As análises } \\
\text { estatísticas utilizadas não permitiram uma } \\
\text { compreensão das relações entre atitudes, } \\
\text { espaços emocionais e comportamentos, ou } \\
\text { seja, como se influenciam entre si, se há } \\
\text { relações de dependência, interveniência ou } \\
\text { antecedência. }\end{array}$ & $\begin{array}{l}\text { Verificar a influência da marca sobre as atitudes, } \\
\text { emoções e comportamento dos consumidores do } \\
\text { segmento prestígio. Existem diferentes percepções } \\
\text { quanto ao valor da marca de luxo brasileira em } \\
\text { relação às importadas? Qual a influência do local } \\
\text { de origem dos produtos sobre as opiniões dos } \\
\text { consumidores? Quais marcas são mais associadas } \\
\text { ao universo do luxo? Quais marcas se ajustam } \\
\text { melhor a conceitos do segmento do Novo Luxo e } \\
\text { como lançar essas bases no mercado? Quais são as } \\
\text { bases da rejeição do conceito luxo de parte de } \\
\text { alguns consumidores e como neutralizar essa visão }\end{array}$ \\
\hline
\end{tabular}


negativa? Quais as relações entre luxo, consumismo e materialismo? Quais as relações entre luxo e consumo consciente?.

A dificuldade de se conhecer em profundidade um número significativo de pessoas que consomem roupas e acessórios de grifes pirateados, as dificuldades de se

D4 pesquisar além da cidade de Belo Junqueira Horizonte, devido a fatores como custos e (2012) tempo, impossibilitaram a pesquisa de ter uma maior abrangência, e restringem sua generalização e validade para o grupo pesquisado.

\begin{tabular}{|c|c|}
\hline $\begin{array}{c}\text { D5 } \\
\text { Kikko } \\
(2012)\end{array}$ & Inobservado. \\
\hline $\begin{array}{c}\text { D6 } \\
\text { Lannes } \\
(2009)\end{array}$ & Inobservado. \\
\hline $\begin{array}{l}\text { D7 } \\
\text { Leite } \\
(2012)\end{array}$ & $\begin{array}{l}\text { Os resultados da pesquisa estão } \\
\text { condicionados primeiramente ao contexto } \\
\text { no qual o estudo empírico foi aplicado. } \\
\text { Utilizou-se poucos construtos para estudar } \\
\text { as possíveis relações com a pirataria de } \\
\text { jogos de vídeo game e, dessa forma, não } \\
\text { foi possível provar as hipóteses propostas. }\end{array}$ \\
\hline $\begin{array}{l}\text { D8 } \\
\text { Machado } \\
(2011)\end{array}$ & $\begin{array}{l}\text { Segmento de mercado limitado, } \\
\text { representado por empresas multinacionais } \\
\text { fabricantes de medicamentos de disfunção } \\
\text { erétil, que tem peculiaridades distintas. }\end{array}$ \\
\hline
\end{tabular}

A falta de abordagem da relação entre a identidade e imagem das empresas de luxo D9 no Brasil, aliada a pequena literatura desse Martins segmento e de estudos sobre o tamanho do (2009) mercado de luxo no país limitam a pesquisa teórica. A técnica de observação direta pode ser uma limitação.

Tratou-se de uma amostra nãoprobabilística, o que dificulta análises mais D10 amplas e generalizadas sobre a população. Martins Além disso, a utilização de ferramentas (2012) on-line para coleta de dados, permite análise apenas para população de usuários de internet. A maior parte da amostra foi composta pelos contatos do autor.

A principal limitação da pesquisa está no insucesso da manipulação da vergonha no segundo experimento.

D11

Ribeiro

(2015)
Estudar como ocorre a apropriação dos significados das grifes pelo indivíduo, sob o modelo do movimento do significado. Pode-se também estudar como os símbolos e seus significados interferem na escolha de determinadas grifes em detrimento a outras. Ou, até mesmo, compreender as relações sociais que são construídas ou constituídas em torno de um objeto de grife, bem como os fatores culturais que influenciam nas decisões de consumo por uma roupa e acessório de grife falsificado.

Inobservado.

Análise da precificação da música em função de seu efeito de valorização de negócios e marcas. Tal tema preencheria uma importante lacuna para o futuro do negócio das gravadoras no novo modelo econômico.

Aplicar outros construtos relacionados como, por exemplo, incluir a cultura, a noção de direito criminal e de direitos autorais e o conhecimento que o usuário possui das novas formas de comunicação, compartilhamento de arquivos e realização de cópias, por exemplo.

Verificar o papel que o ambiente institucional, principalmente nos países emergentes como o Brasil, exerce na formulação das estratégias de não-mercado.

O estudo do perfil econômico do consumidor brasileiro, a expansão das marcas de moda de luxo no Brasil frente ao mercado aqui existente, a profissionalização das empresas de moda de luxo presentes no pais e o sistema de tributação e seus efeitos sobre a importação de produtos de luxo no Brasil. Outro tema de estudo importante é a opinião dos consumidores.

Inobservado.

Testar outras formas de manipular a vergonha por instrução em experimentos, com o uso de vídeos ou imagens, por exemplo. Sugere-se também investigações adicionais sobre o efeito da qualidade da falsificação na relação entre vergonha e comportamentos de consumo de falsificados. Sugere-se ainda explorar melhor o efeito moderador das variáveis demográficas, como renda e gênero, na relação entre vergonha e consumo de falsificados.

D12 Amostra homogênea, podendo inferir em Investigar a pouca flexibilidade da indústria 
Santos

Junior

(2009) resultados com pouca variabilidade. fonográfica frente aos downloads gratuitos, como também aprofundar o estudo das variáveis abordadas, além de analisar outras não consideradas. Poderiam ser feitos estudos que avaliassem o impacto destes downloads nos números das bilheterias de cinema e de vendas de DVDs, além de todos os outros elementos que compõem a cadeia.

Diversificar o perfil do entrevistado. Talvez uma etnografia realizada junto a uma comunidade carente possa revelar aspectos até agora não descobertos.

Vieira Dessa forma, as informações obtidas

(2006) refletem um universo pequeno, mas representativo, de opiniões e impressões.

Os entrevistados afirmaram serem Verificar o impacto junto ao consumidor de consumidores de produtos falsificados de forma espontânea. Sugere-se que T1 consumidores de falsificados que Strehlau escondam o consumo possam trazer (2004) achados relevantes. A amostra utilizada não permite a estrapolação dos dados. Não foi abordada a compra não intencional, aquela que o consumidor não está ciente da falsificação. produtos de luxo em diferentes cidades e países. Investigar o papel da internet na compra de produtos falsificados. Estudar o caso particular de determinados produtos.

Fonte: desenvolvido pelos autores (2015).

Os avanços advindos das dissertações e tese analisadas são diversos e em sua maioria as hipóteses de pesquisa foram confirmadas nos estudos descritivos. Já estudos exploratórios conseguiram responder aos objetivos propostos. O Quadro 19 dispõe dos principais resultados alcançados pelos pesquisadores.

Quadro 19: Contribuições do estudo

\begin{tabular}{|c|c|}
\hline Código & Contribuições do estudo \\
\hline $\begin{array}{l}\text { D1 } \\
\text { Casali } \\
(2011)\end{array}$ & $\begin{array}{l}\text { Os resultados indicam que a responsabilidade social do consumidor influencia muito pouco o } \\
\text { comportamento de consumo de produtos piratas, tanto na intenção de compra quanto na prática, } \\
\text { sendo comportamento ético ou honesto do consumidor a única dimensão que influencia de forma } \\
\text { estatisticamente significativa. }\end{array}$ \\
\hline $\begin{array}{l}\text { D2 } \\
\text { Ferreira } \\
(2007)\end{array}$ & $\begin{array}{l}\text { O aspecto mais recorrente nas entrevistas com os consumidores de falsificações foi o valor para o } \\
\text { consumidor como diversão [prazer], seguido do valor como estima e como status, para só então } \\
\text { os valores como excelência, eficiência, ética e altruísmo serem observados. Todavia, o valor para } \\
\text { o consumidor como estética não foi apontado nos depoimentos analisados. }\end{array}$ \\
\hline $\begin{array}{l}\text { D3 } \\
\text { Galhanone } \\
(2008)\end{array}$ & $\begin{array}{l}\text { Revelou a existência de três grupos com perfis diferenciados em termos de atitudes e crenças } \\
\text { com respeito ao luxo. Indicou ainda que o consumo do luxo pode ser relacionado à tradição } \\
\text { social, imagem ou expressão pessoal ou a um mecanismo de premiação. }\end{array}$ \\
\hline $\begin{array}{l}\text { D4 } \\
\text { Junqueira } \\
\text { (2012) }\end{array}$ & $\begin{array}{l}\text { Constatou-se que o uso de roupas ou acessórios de grifes, mesmo que pirateados, garante, em } \\
\text { parte, no âmbito micro social do indivíduo, o sucesso, o glamour, o sentimento de pertença, a } \\
\text { satisfação de poder comprar e o preenchimento de parte de seus vazios, proporcionando-lhe um } \\
\text { sentimento de conquista e uma melhora na relação do sujeito consigo mesmo e com seu meio. }\end{array}$ \\
\hline D5 & O trabalho desenvolveu quatro possíveis cenários futuros para a indústria fonográfica, são eles: \\
\hline $\begin{array}{l}\text { Kikko } \\
(2012)\end{array}$ & Oligopólio musical, A vez das editoras, A ascensão de milhares e Primavera musical. \\
\hline $\begin{array}{l}\text { D6 } \\
\text { Lannes } \\
(2009)\end{array}$ & $\begin{array}{l}\text { Pode-se observar que houve uma mudança no posicionamento das gravadoras, que já tentam se } \\
\text { estabelecer como fornecedoras de entretenimento ligado à música, com o objetivo de buscar } \\
\text { resultados econômicos a partir de novas origens de receita, da diversificação de seus negócios. }\end{array}$ \\
\hline $\begin{array}{l}\text { D7 } \\
\text { Leite } \\
(2012)\end{array}$ & $\begin{array}{l}\text { Os resultados indicam que a responsabilidade social do consumidor e o materialismo não } \\
\text { influenciam o comportamento de pirataria de jogos de videogames, seja na intenção, na prática } \\
\text { ou na favorabilidade, sendo comportamento ético ou honesto do consumidor a única dimensão } \\
\text { que o influenciou, sutilmente, de forma estatisticamente significativa. }\end{array}$ \\
\hline
\end{tabular}




\begin{tabular}{|c|c|}
\hline $\begin{array}{l}\text { D8 } \\
\text { Machado } \\
(2011)\end{array}$ & $\begin{array}{l}\text { Mostrou que as empresas pesquisadas usam as ações coletivas coordenadas para dialogar com o } \\
\text { Governo e utilizam a estratégia de prover informação para as Instituições Governamentais. }\end{array}$ \\
\hline $\begin{array}{l}\text { D9 } \\
\text { Martins } \\
(2009)\end{array}$ & $\begin{array}{l}\text { Apontou para características que definem o comportamento do consumidor de luxo em relação as } \\
\text { marcas de moda de luxo internacionais e os fatores que os levam a preferi-las ou rejeita-as. } \\
\text { Também evidencia diferenças entre a identidade e a imagem da Louis Vuitton no Brasil. }\end{array}$ \\
\hline $\begin{array}{l}\text { D10 } \\
\text { Martins } \\
(2012)\end{array}$ & $\begin{array}{l}\text { As principais descobertas foram: 1) } 88,5 \% \text { dos internautas são usuários de música digital; 2) seu } \\
\text { perfil está significativamente relacionado com o perfil de uso da internet (redes sociais e } \\
\text { entretenimento); 3) os não- usuários deixam de utilizar música digital principalmente pela falta } \\
\text { de conhecimento de como fazê-lo; 4) } 66,4 \% \text { das pessoas tem intenção de pagar pela música } \\
\text { digital; 5) e compartilham uma característica: compram com frequência pela internet; } 6 \text { ) pessoas } \\
\text { com intenção de pagar pela música digital percebem a diferença entre música legal e ilegal além } \\
\text { de atribuir baixo grau de importância para a internet. }\end{array}$ \\
\hline $\begin{array}{l}\text { D11 } \\
\text { Ribeiro } \\
(2015)\end{array}$ & $\begin{array}{l}\text { Mostrou um efeito moderador inesperado da renda na relação entre antecipação da vergonha e } \\
\text { intenção de compra de falsificados. A antecipação da vergonha reduz a intenção de compras em } \\
\text { consumidores com renda mais alta. }\end{array}$ \\
\hline $\begin{array}{l}\text { D12 } \\
\text { Santos } \\
\text { Junior } \\
(2009)\end{array}$ & $\begin{array}{l}\text { Confirmou que há relação entre o maior acesso à tecnologia e o estímulo ao download gratuito de } \\
\text { músicas pela Internet. Notou-se ainda que a percepção de injustiça por parte dos consumidores } \\
\text { em relação ao preço praticado pela indústria fonográfica pode incrementar o download gratuito } \\
\text { de arquivos musicais, bem como se percebe a influência da faixa etária no consumo de músicas } \\
\text { obtidas pelo download gratuito. }\end{array}$ \\
\hline $\begin{array}{c}\text { D13 } \\
\text { Vieira } \\
(2006)\end{array}$ & $\begin{array}{l}\text { O consumo socialmente irresponsável foi definido como aquele em que o indivíduo não leva em } \\
\text { consideração as consequências públicas e privadas do seu consumo. Não obstante, foram } \\
\text { identificados, a partir da literatura existente, e a partir do trabalho de campo, fatores } \\
\text { influenciadores no processo decisório do consumidor categorizados, em fatores demográficos, } \\
\text { fatores externos e fatores internos (psicográficos). }\end{array}$ \\
\hline $\begin{array}{c}\mathrm{T} 1 \\
\text { Strehlau } \\
(2004)\end{array}$ & $\begin{array}{l}\text { A teoria de habitus de Bourdieu pode fornecer uma explicação baseada no espaço de posições } \\
\text { sociais organizada em dimensões, sendo que o volume total de capital social, cultural e } \\
\text { econômico, sua composição e trajetória no tempo, pode permear a forma cultural do capital } \\
\text { incorporada. O estudo concluiu ainda que a forma dos consumidores se relacionar com o produto } \\
\text { falsificado, o modo de usar, como abordar o assunto com as outras pessoas numa interação social, } \\
\text { proporciona uma exibição do habitus no contexto social. Considera-se que a ancestralidade no } \\
\text { estrato de elite pode assegurar uma tranquilidade no consumo de falsificados, porque, como } \\
\text { influenciadores sociais, podem expressar sua distância da necessidade e sua possibilidade de } \\
\text { impor as regras de distinção comumente empregadas. }\end{array}$ \\
\hline
\end{tabular}

Fonte: desenvolvido pelos autores (2015).

Destaca-se que o Quadro 19 não busca elencar todas as contribuições dadas pelas dissertações e tese analisadas, mas apresenta em síntese aquilo que se observa nos estudos. Considera-se que o tema falsificação no Brasil é recente e as transformações do mercado ilegal se dão na mesma velocidade da transformação do mercado legal.

Com o objetivo de identificar a quantidade de citações que ocorreram entre artigos, dissertações e tese, realizou-se, por meio do quadro 20, uma estruturação na tentativa de elencar as pesquisas que foram citadas em maior frequência. 
Gráfico 20: Frequência de citação dos artigos

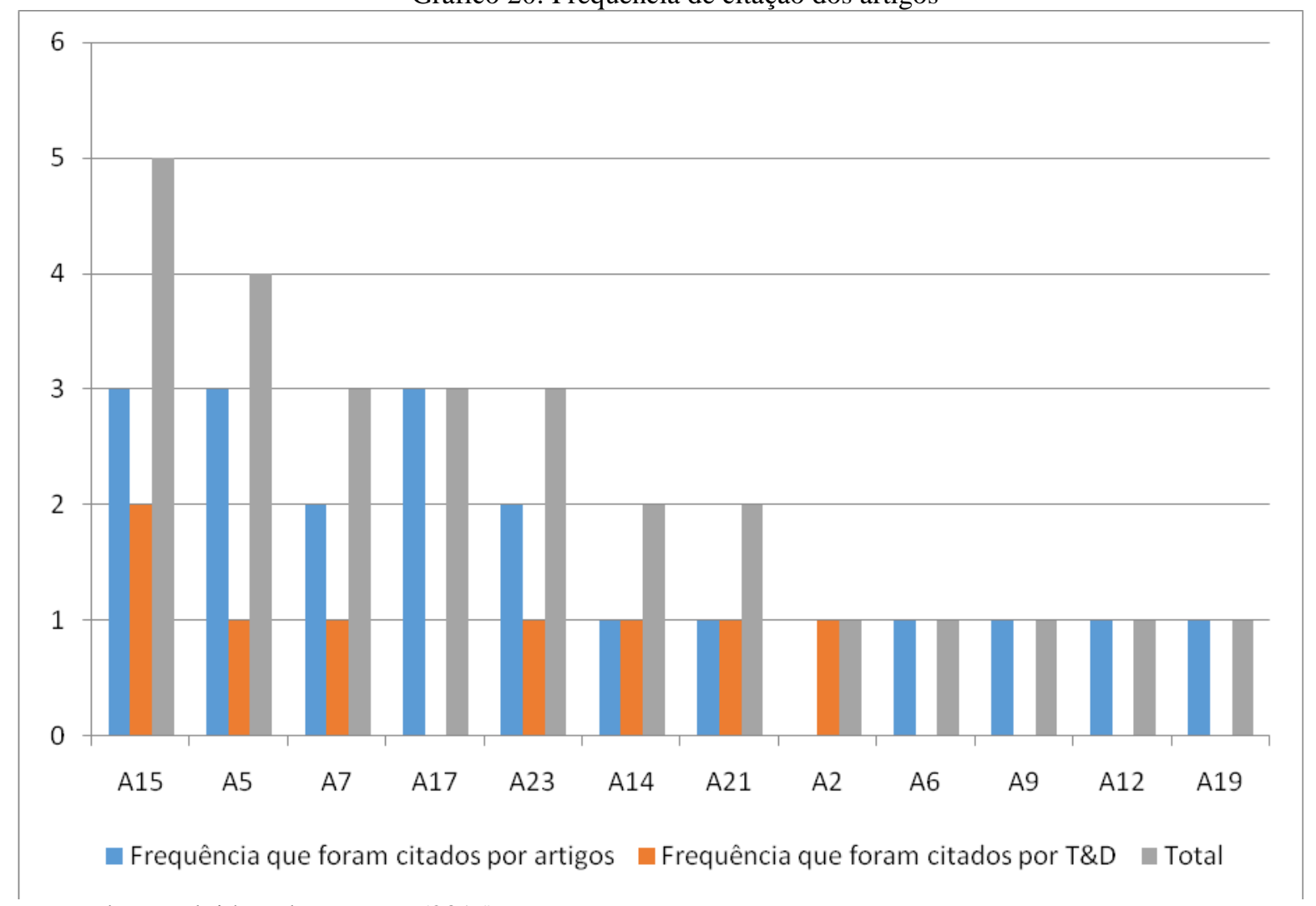

Fonte: desenvolvido pelos autores (2015).

Como observado no 1 ocorreu mais que o dobro de citações entre artigos do que em dissertações e tese. Foi observado também que aproximadamente metade dos artigos publicados citaram outros artigos. Pôde-se observar que há maior presença de citações de artigos em teses e dissertação. Constata-se, por meio do Gráfico 21, que houve pouca citação entre as dissertações e tese, o que indica que tais trabalhos tendem a ser negligenciados pelos estudos da área. 
Gráfico 21: Frequência de citação das dissertações e tese

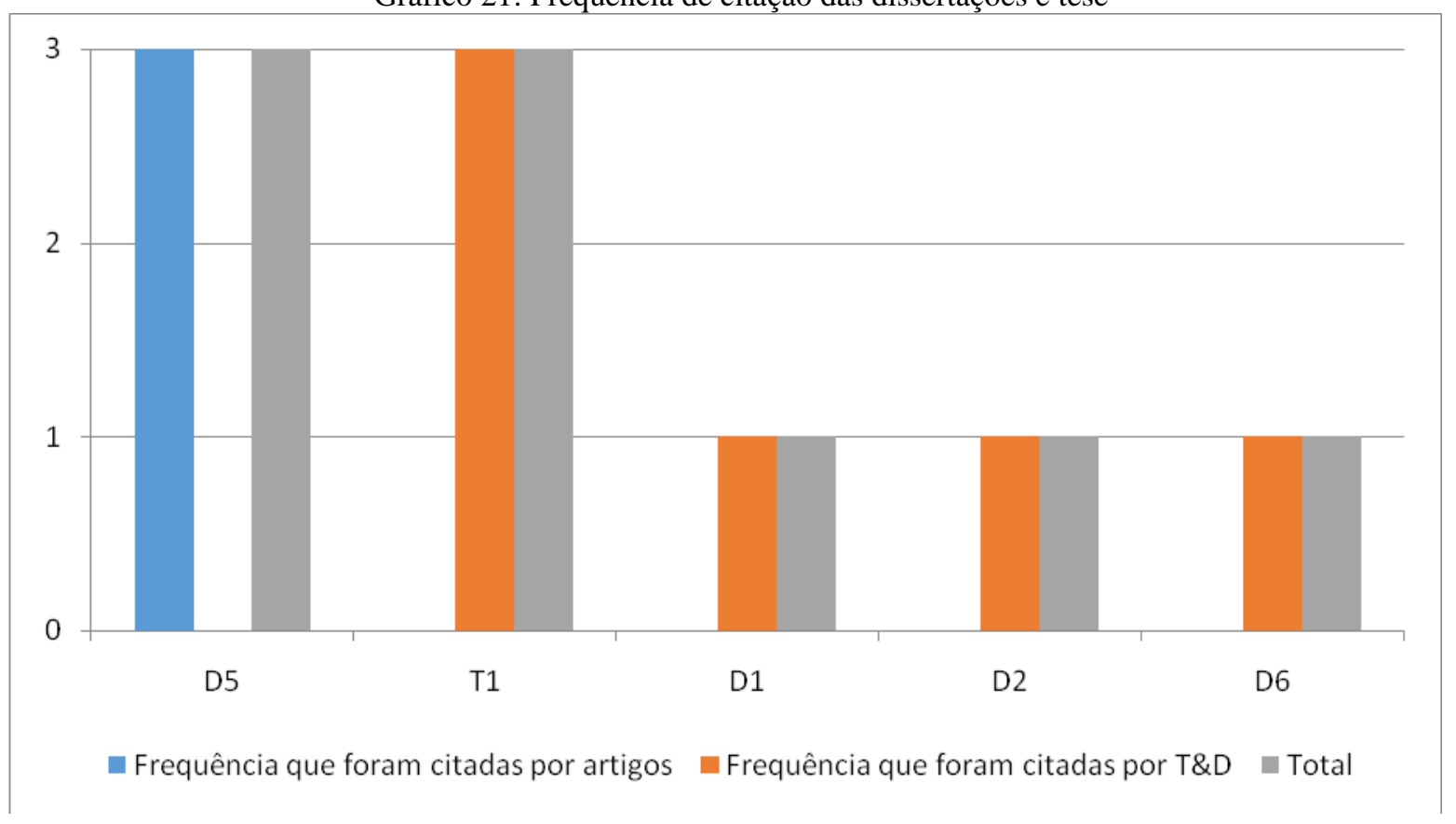

Fonte: desenvolvido pelos autores (2015).

O que se observa é que a tese foi citada por metade dos outros trabalhos stricto sensu. Além disso, as T\&D foram utilizadas em maior frequência do que artigos na elaboração das pesquisas. Vale ressaltar que os trabalhos do corpus de pesquisa que não foram citados por outros artigos, dissertações e tese foram excluídos da análise.

Nesse sentido, foi realizado o levantamento dos pesquisadores com maior número de publicações. Por meio do Quadro21, observa-se que seis pesquisadores contribuíram com um terço de todas as publicações analisadas pelo presente estudo.

Quadro 21: Pesquisadores com maior número de publicações

\begin{tabular}{c|c}
\hline Pesquisador(a) & Quantidade de pesquisas publicadas \\
\hline Arnaldo Luiz Ryngelblum & 6 \\
\hline Suzane Strehlau & 6 \\
\hline Solange Gualberto da Mata Machado & 4 \\
\hline Ernesto Michelangelo Giglio & 3 \\
\hline Richélita do Rosário Brito Casali & 3 \\
\hline Denise Franca Barros & 2 \\
\hline Subtotal & 24 \\
\hline
\end{tabular}

Fonte: desenvolvido pelos autores (2015).

Observa-se que os dois pesquisadores que mais publicaram sobre falsificação responderam, cada um, por $16 \%$ de todas as publicações analisadas. O Quadro21 relacionou todos os pesquisadores do corpus da pesquisa que publicaram mais de uma pesquisa sobre o tema. 


\section{CONCLUSÕES E CONSIDERAÇÕES FINAIS}

Apesar do corpus de pesquisa ser recente no Brasil, observa-se significativos avanços para entendimento do fenômeno. De uma forma geral, observou-se uma predominância de estudos sobre falsificação na área de marketing, embora o tema tenha sido abordado por outras áreas de conhecimento. Em termos de setores da economia, a indústria fonográfica e a de software foram as mais pesquisadas. Para a fundamentação teórica, os estudos não se limitam à área de falsificação e normalmente contemplam teorias ligadas à outras temáticas, sendo mais recorrentes aquelas ligadas à área de marketing. Foi observado que há uma maior citação de artigos do que de dissertações e teses pelos estudos analisados. Nesse sentido, os professores Arnaldo Luiz Ryngelblum e Suzane Strehlau foram os autores mais profícuos dos trabalhos analisados, com 6 publicações cada, sendo que Strehlau foi a autora da tese analisada, enquanto Ryngelblum participou apenas de artigos. Não por acaso, tais autores foram os mais citados pelos trabalhos analisados.

Em relação aos objetivos do estudo, pode-se perceber que as características gerais das publicações são heterogêneas, o que também se observa nos métodos de coleta e análise dos dados. Os conceitos e teorias que embasaram os trabalhos apresentaram diversas referências que podem ser utilizadas por futuros pesquisadores sobre o tema. As sugestões para futuras pesquisas e as limitações do estudo se dão, de forma resumida, nos aspectos metodológicos dos trabalhos.

Além dos objetivos da pesquisa, pode-se observar que, no momento da busca por teses e dissertações, muitos programas de pós-graduação em Administração não dispunham do texto integral das dissertações e teses. Futuros estudos bibliométricos, meta-etnográficos, metanarrativos ou meta-analíticos, no Brasil, que considerarem dissertações e teses como corpus de pesquisa, poderão passar pelo mesmo problema. Nesse sentido, sugere-se que as instituições disponibilizem em seus bancos de dados as teses e dissertações desenvolvidas por seus programas stricto sensu, permitindo acessar o material com maior facilidade.

Para futuros estudos que tratam da falsificação, poderia ser utilizada abordagem qualitativa com metodologia etnográfica ou observação participante, podendo proporcionar descobertas para o entendimento do fenômeno. Sugere-se também que novos estudos, de natureza quantitativa, adotem amostras probabilísticas, para que seus resultados possam ser extrapolados.

Como os trabalhos demonstraram, a falsificação é um amplo campo de estudo ainda a ser explorado. Acredita-se que futuros trabalhos poderão lançar luz em abordagens, objetos de estudos e teorias ainda pouco abordados neste campo de estudo. Nesse sentido, sugere-se a

REAd | Porto Alegre - Edição 86 - No 2 - Maio / Agosto 2017 - p. 135 - 166 
interlocução com outras áreas do conhecimento, o que poderia proporcionar novas perspectivas sobre o fenômeno.

O mercado de produtos falsificados se mostra dinâmico e complexo. Assim, como sugestão para futuros estudos, parece pertinente abordar outros segmentos da economia, como bebidas, medicamentos, alimentos, vestuário, calçados, peças automotivas, cigarros, etc. Outra sugestão seria abordar o consumo de produtos falsificados em que a marca não é fator de distinção, ou o efeito trickle-down aplicado ao consumo de produtos de massa.

Com base nos trabalhos analisados, constatou-se um gap de pesquisa sobre falsificação da área de Administração no Brasil, que seria a análise da produção e/ou comercialização de tais produtos. Estudos que abordem a falsificação sob o lado da oferta poderiam trazer contribuições até agora não observadas na produção científica analisada, principalmente quando se considera que o país se destaca não só como consumidor, mas também como produtor de tais produtos (SILK, 1986; STUMPF; CHAUDHRY; PERRETTA, 2013; STUMPF; CHAUDHRY, 2010).

Como limitações do presente estudo, deve-se reconhecer que o mapeamento metanarrativo, apesar de buscar se ater ao material analisado e reduzir os aspectos subjetivos do pesquisador, envolve interpretação de informações para a categorização da publicação. Nesse sentido, há de se considerar que o processo de categorização pode abarcar erros de interpretação do item categorizado. Além disso, o corpus analisado ficou restrito a estudos da área de Administração, o que pode ser visto como outra limitação.

Para futuros mapeamentos meta-narrativos, sugere-se a replicação do método em novos estudos sobre falsificação no Brasil extrapolando à área de conhecimento da Administração e o aperfeiçoamento do método proposto.

\section{REFERÊNCIAS}

ANWAR MIR, I. Examination of attitudinal and intentional drivers of non-deceptive counterfeiting in a South Asian context. Journal of Business Economics and Management, Abingdon, v. 14, n. 3, p. 601-615, 2013.

BASCAP - Business Action to Stop Counterfeiting and Piracy. Estimating the global economic and social impacts of counterfeiting and piracy: A report commissioned by business action to stop counterfeiting and piracy (BASCAP). Fev. 2011. Disponível em: $<$ https://cdn.iccwbo.org/content/uploads/sites/3/2016/11/ICC-BASCAP-Global-Impacts-FullReport-2011.pdf>.

BERTERO, C. O.; CALDAS, M. P.; WOOD JR, T. Produção científica em administração de empresas: provocações, insinuações e contribuições para um debate local. Revista de 
Administração Contemporânea, São Paulo, v. 3, n. 1, p. 147-178, 1999.

BIAN, X.; VELOUTSOU, C.. Consumer's attitudes regarding non-deceptive counterfeit brands in the UK and China. Journal of Brand Management, New York, v. 14, n. 3, p. 211 $222,2007$.

CHAKRABORTY, G. et al. Use of negative cues to reduce demand for counterfeit products. Advances in Consumer Research, Duluth, v. 24, 1997.

CHAUDHRY, P. E. Changing levels of intellectual property rights protection for global firms: A synopsis of recent US and EU trade enforcement strategies. Business Horizons, Amsterdam, v. 49, n. 6, p. 463-472, 2006.

CHAUDHRY, Peggy E.; ZIMMERMAN, Alan; PETERS, Jonathan R.; CORDELL, Victor V. Preserving intellectual property rights: Managerial insight into the escalating counterfeit market quandary. Business Horizons, Amsterdam, v. 52, n. 1, p. 57-66, 2009.

DAVEL, Eduardo; ALCADIPANI, Rafael. Estudos críticos em administração: aprodução científica brasileira nos anos 1990. Revista de Administração de Empresas, São Paulo, v. 43, n. 4, p. 72-85, 2003.

ECONOMIST, T. Imitating property is theft. Acesso em 17 de junho, 2015. Disponível em: <http://www.economist.com/node/1780818>.

EISEND, M.; SCHUCHERT-GÜLER, P. Explaining counterfeit purchases: A review and preview. Academy of Marketing Science Review, New York, v. 2006, p. 1, 2006.

FNCP - Fórum Nacional Contra a Pirataria e a Ilegalidade. Entrevista com o advogado André Almeida, Membro titular do Conselho Nacional de Combate à Pirataria. 24 de março, 2015. Disponível em:

〈http://www.forumcontrapirataria.org/web/forum/entrevista/31 >.

FROMAN, M. B. G. National Trade Estimate Report on Foreign Trade Barriers. Special Report. Washington DC, 2015. Disponível em:

<https://ustr.gov/sites/default/files/2015\%20NTE\%20Combined.pdf >.

GREEN, R. T.; SMITH, T. Countering brand counterfeiters. Journal of international Marketing, Chicago, v. 10, n. 4, p. 89-106, 2002.

LEE, S. H.; YOO, B. A review of the determinants of counterfeiting and piracy and the proposition for future research. The Korean Journal of Policy Studies, Seoul, v. 24, n.1, p. $1-38,2009$.

MACESICH, G. Counterfeit Detectors and Pre-1860 Monetary Statistics. The Journal of Southern History, Hanover, v. 27, n. 2, p. 229-232, 1961.

MARTINS, J. P. C. O mercado de musica digital brasileiro: um estudo sobre o comportamento brasileiro. 2012. Dissertação (Mestrado) - Universidade Federal do Rio Grande do Sul. Programa de Pós-Graduação em Administração, Porto Alegre, 2012. 
MATOS, C. A.; ITUASSU, C. T. Comportamento do consumidor de produtos piratas: os fatores influenciadores das atitudes e das intenções de compra. In: ENCONTRO NACIONAL DA ANPAD, 29., Brasília, 2005. Anais... Brasília: ANPAD, 2005.

PETTICREW, M.; ROBERTS, H. Systematic reviews in the social sciences: A practical guide. Hoboken: John Wiley \& Sons, 2006.

PHAU, I.; TEAH, M. Devil wears (counterfeit) Prada: a study of antecedents and outcomes of attitudes towards counterfeits of luxury brands. Journal of Consumer Marketing, Bingley, v. 26, n. 1, p. 15-27, 2009.

PINTO, M. R.; LARA, J. E. A pesquisa na área do comportamento do consumidor: uma análise da produção acadêmica brasileira entre 1997 e 2006. In: ENCONTRO NACIONAL DA ASSOCIAÇÃO DE PÓS-GRADUAÇÃO E PESQUISA EM ADMINISTRAÇÃO, 31., Brasília, 2007. Anais... Brasília: ANPAD, 2007.

RADON, A. Counterfeit luxury goods online: an investigation of consumer perceptions. International Journal of Marketing Studies, [s.1.], v. 4, n. 2, p. 74, 2012.

RYNGELBLUM, A. L. Tratamento da pirataria pelas empresas e pelas teorias de estratégia. In: ENCONTRO DE ESTUDOS EM ESTRATÉGIA DA ANPAD, 2., Rio de Janeiro, 2005. Anais... Rio de Janeiro: ANPAD, 2005.

RYNGELBlUM, A. L.; GIGLIO, E. M. As Políticas Públicas no Combate à Pirataria: Reflexões sobre a Prática da Gestão Pública. In: ENCONTRO NACIONAL DE ESTUDOS ORGANIZACIONAIS DA ANPAD, Rio de Janeiro, 2008. Rio de Janeiro: ANPAD, 2008.

SAMPAIO, C. H.; PERIN, M. G; Pesquisa científica da área de marketing: uma revisão histórica. Revista de Administração Contemporânea, São Paulo, v. 10, n. 2, p. 179-202, 2006.

SANTOS JUNIOR, M. F. Os fatores que influenciam o download gratuito de música na internet. 2009. Dissertação (Mestrado) - Fundação Getúlio Vargas. Escola Brasileira de Administração Pública e de Empresas, Rio de Janeiro, 2009.

SAUERBRONN, J. F.; BARROS, D. F.; STREHLAU, S.; COSTA, A. S. M.. Pirataria e Download como comportamento desviante desviante e as técnicas de neutralizaçãousadas pelos consumidores. Gestão e Sociedade, Belo Horizonte, v. 4, n. 8, p. 513-538, 2011.

SILK, M. A. Legal Efforts of the United States and the Republic of China of Taiwan at Controlling the Transnational Flow of Commercial Counterfeit Goods. Maryland Journal of International Law and Trade, Maryland, v. 10, p. 210-229, 1986.

STAAKE, T.; THIESSE, F.; FLEISCH, E. The emergence of counterfeit trade: a literature review. European Journal of Marketing, Bingley, v. 43, n. 3/4, p. 320-349, 2009.

STUMPF, S. A.; CHAUDHRY, P. Country matters: Executives weigh in on the causes and counter measures of counterfeit trade. Business Horizons, Amsterdam, v. 53, n. 3, p. 305$314,2010$. 
STUMPF, S. A.; CHAUDHRY, P. E.; PERRETTA, L. Fake: can business stanch the flow of counterfeit products? Journal of Business Strategy, Bingley, v. 32, n. 2, p. 4-12, 2011.

TSAI, M. F.; CHIOU, J. R. Counterfeiting, enforcement and social welfare. Journal of Economics, New York, v. 107, n. 1, p. 1-21, 2012.

WILCOX, K.; KIM, H. M.; SEN, S. Why do consumers buy counterfeit luxury brands? Journal of Marketing Research, Chicaco, v. 46, n. 2, p. 247-259, 2009. 